\title{
Synthesis, Properties, and Applications of Low-Dimensional Carbon-Related Nanomaterials
}

\author{
Ali Mostofizadeh,, ${ }^{1}$ Yanwei Li, ${ }^{1}$ Bo Song, ${ }^{1}$ and Yudong Huang ${ }^{1}$ \\ ${ }^{1}$ Department of Polymer Science and Engineering, School of Chemical Engineering and Technology, \\ Harbin Institute of Technology, Harbin 150001, China \\ ${ }^{2}$ Nuclear Science and Technology Research Institute (NSTRI), P.O. Box 11365-8486, Tehran, Iran \\ Correspondence should be addressed to Yudong Huang, ydhuang.hit1@yahoo.com.cn
}

Received 15 June 2010; Accepted 1 November 2010

Academic Editor: Sulin Zhang

Copyright ( $) 2011$ Ali Mostofizadeh et al. This is an open access article distributed under the Creative Commons Attribution License, which permits unrestricted use, distribution, and reproduction in any medium, provided the original work is properly cited.

In recent years, many theoretical and experimental studies have been carried out to develop one of the most interesting aspects of the science and nanotechnology which is called carbon-related nanomaterials. The goal of this paper is to provide a review of some of the most exciting and important developments in the synthesis, properties, and applications of low-dimensional carbon nanomaterials. Carbon nanomaterials are formed in various structural features using several different processing methods. The synthesis techniques used to produce specific kinds of low-dimensional carbon nanomaterials such as zero-dimensional carbon nanomaterials (including fullerene, carbon-encapsulated metal nanoparticles, nanodiamond, and onion-like carbons), one-dimensional carbon nanomaterials (including carbon nanofibers and carbon nanotubes), and two-dimensional carbon nanomaterials (including graphene and carbon nanowalls) are discussed in this paper. Subsequently, the paper deals with an overview of the properties of the mainly important products as well as some important applications and the future outlooks of these advanced nanomaterials.

\section{Introduction}

Carbon (from the Latin language, Carbo means coal) as a non-metal element can be found in every living organism; therefore, it can be bravely confirmed that the basis of one aspect of life is carbon. Carbon, as the original component presented in millions of various compounds, is capable to be very hard such as diamond or very soft as graphite. The use of this unique chemical element is almost unlimited from the hardest diamond for drilling to the softest form, graphite, for using as a lubricant in skin health and beauty. This nontoxic element is used as a filter to reduce other toxins. It has the highest melting point among all the known elements and occurs free in nature. On the other hand, carbon nanomaterials are known as the chemical fruits of the mother tree of carbon and most importantly carbon 60 molecules. Since a series of exciting carbon nanomaterials are arising, they have attracted tremendous attention and have been intensively studied on numerous carbon-based nanomaterials because of their unique structure, electronic, mechanical, optical, and chemical characteristics. Low-dimensional carbon nanomaterials can be divided into categories of different dimensionality ranging from zero-dimensional (0-D) to onedimensional (1-D) and two-dimensional (2-D) depending on their nanoscale range $(<100 \mathrm{~nm})$ in different spatial directions. The representatives in family of low-dimensional carbon nanomaterials focus on fullerene, onion-like carbon, carbon-encapsulated metal nanoparticles, nanodiamond (0D), carbon nanofibers, carbon nanotubes (1-D), graphene, and carbon nanowall (2-D).

As a brief history, it is worth to remember that in 1952 Radushkevich and Lukyanovich introduced the hollow graphitic carbon fibers with $50 \mathrm{~nm}$ in diameter in the Soviet Journal of Physical Chemistry mentioned in [1]. In 1960, Bollmann and Spreadborough [2] showed the structure of multiwall carbon nanotubes (MWNTs) using an electron microscope. They investigated the friction properties of carbon due to rolling sheets of graphene in "Nature" [2]. In 1976, Oberlin et al. [3] showed the CVD growth of nanometer-scale carbon fibers. In 1985, the revolutionary 
discovery in this area occurred, which was the discovery of fullerenes by Kroto et al. [4]. The discovery of fullerene seems to be very important because it might be the first new allotrope of carbon to be discovered in the 20th century [5]. The nickname for fullerene comes from Richard Buckminster "Bucky" Fuller (July 12, 1895-July 1, 1983), an American architect, author, designer, inventor, and futurist who used geodesic spheres structures in his work. Other important well-known carbon nanomaterials are carbon nanotubes (CNTs) which will be introduced with the full features and aspects in this paper. As a pictorial introduction, we have summarized the main structures of various lowdimensional carbon nanomaterials in Figure 1 [6-11].

In the past decade, by using nanotechnology and carbonbased nanomaterials, the world might be able to see an industrial revolution surpassing any one before. This new technology could end the world's hunger, make affordable goods, have massive implications for medical breakthroughs, and unfortunately also be used in military applications. In this paper, we will discuss the synthesis, properties, and applications of these characteristic examples as well as the latest research results and developments, that hopefully more researchers can address the area and look forward to more research results.

\section{Carbon Nanomaterials Synthesis}

In this paper, our purpose is to summarize the well-known methods and to provide recent progress synthesizes of the entire nanostructure class of carbon nanomaterials. Where appropriate, we also provide a short historical background and the structure description of carbon nanomaterials.

\subsection{Zero-Dimensional Carbon Nanomaterials (0-DCNs)}

2.1.1. Fullerene. Fullerenes are spherical, caged molecules with carbon atoms located at the corner of a polyhedral structure consisting of pentagons and hexagons. A spherical fullerene looks like a soccer ball and is often called "buckyball.” Fullerenes were named after Richard Buckminster Fuller, an architect known for the design of geodesic domes which resemble spherical fullerenes in appearance. In fact, fullerenes were discovered as an unexpected surprise during laser spectroscopy experiments in 1985, by researchers at Rice University. As mentioned in the Nobel Prize records at [12], the 1996 Nobel Prize in chemistry was awarded jointly to Robert F. Curl, Jr., Richard E. Smalley, and Sir Harold W. Kroto "for their discovery of fullerenes" [12]. The first method of production of fullerenes shown in Figure 2 by Kroto et al. in 1985 [4] used laser vaporization of carbon in an inert atmosphere in which microscopic amounts of fullerenes were produced. However, for the first time in 1990, the physicists Krätschmer et al. [13] produced isolable quantities of C60 by using an arc to vaporize graphite. The way was thus open for studying an entirely new branch of chemistry. Alekseyev and Dyuzhev [14] systemically discussed fullerene formation in an arc discharge and all the aspects of the problem from arc discharge calculations to the immediate fullerene molecule assembly.

Fullerene chemistry has become a very hot research field in the last two decades. A variety of fullerene derivatives with unique properties were produced, and several techniques for producing them in greater volumes have been suggested. In 1991 and 1992, Howard et al. [15, 16] observed fullerenes C60 and C70 from benzene/oxygen flames and developed a method of synthesis of fullerenes in combustion. On the other hand, Xie et al. [17] synthesized fullerenes C60 and C70 via microwave plasma from chloroform at lowpressure argon atmosphere. The microwave plasma synthesis from chloroform opened a new way to large quantity and low-cost production of fullerenes, various perchlorinated intermediates of fullerenes, and the perchlorinated carbon clusters. Taylor et al. [18] introduced a synthesis of C60 and $\mathrm{C} 70$ by pyrolysis of naphthalene at $1,000^{\circ} \mathrm{C}$. The advantages involve a continuous process that does not require rod replacement, and closed fullerene cages can be prepared from well-defined aromatic fragments. Koshio et al. [19] also used a method of fullerene by pyrolysis ragged singlewall carbon nanotubesntreated by ultrasonication with an organic solvent followed by heating in oxygen gas. As a new event in 2009, Chen and Lou [20] reported that C60 can also be synthesized from the reduction $\mathrm{CO}_{2}$ via metallic lithium or $\mathrm{MgCO}_{3}$ at $700^{\circ} \mathrm{C}$, ca. $100 \mathrm{MPa}$. Although the yield via the above method was low, this method could resolve the biggest contamination problem in the previous synthesis methods and could provide some new insights for the formation of C60.

Koprinarov et al. [21] reported fullerene structures (FSs), and FSs with incorporated iron atoms were obtained via DC arc discharge between carbon electrodes in Ar and ferrocene gas mixture ambient. The method supplied the electrode deposit growth with carbon from the ferrocene, which made fullerene creation easier and increased the product quantity. Richter et al. [22] made a detailed research on the process of fullerene formation in acetylene/oxygen/argon flat flames with adding chlorine and burning at low pressure. Recently, many chemical syntheses of fullerenes also have been reported in [23].

2.1.2. Carbon-Encapsulated Metal Nanoparticles (CEMNPs). Carbon-encapsulated metal (magnetic) nanoparticles (CEMNPs) represent a new class of Zero-dimensional carbon-metal composite nanomaterials. It is the shape of core-shell structure on the nanoscale. The polyhedral metallic core is entirely encapsulated by the multilayer-graphitized carbon shell. So, the carbon layers isolate the particles magnetically from external environment and protect them against corrosion and magnetic coupling between individual particles.

Since the first report on $\mathrm{LaC}_{2}$ encapsulated within nanoscale polyhedral carbon particles in a carbon arc synthesized by Ruoff et al. [24] and Tomita [25] in 1993, carbonencapsulated metal nanoparticles have received considerable attention because of their novel structures and obvious technological promise. Several groups have succeeded in encapsulating various materials into a hollow graphitic 

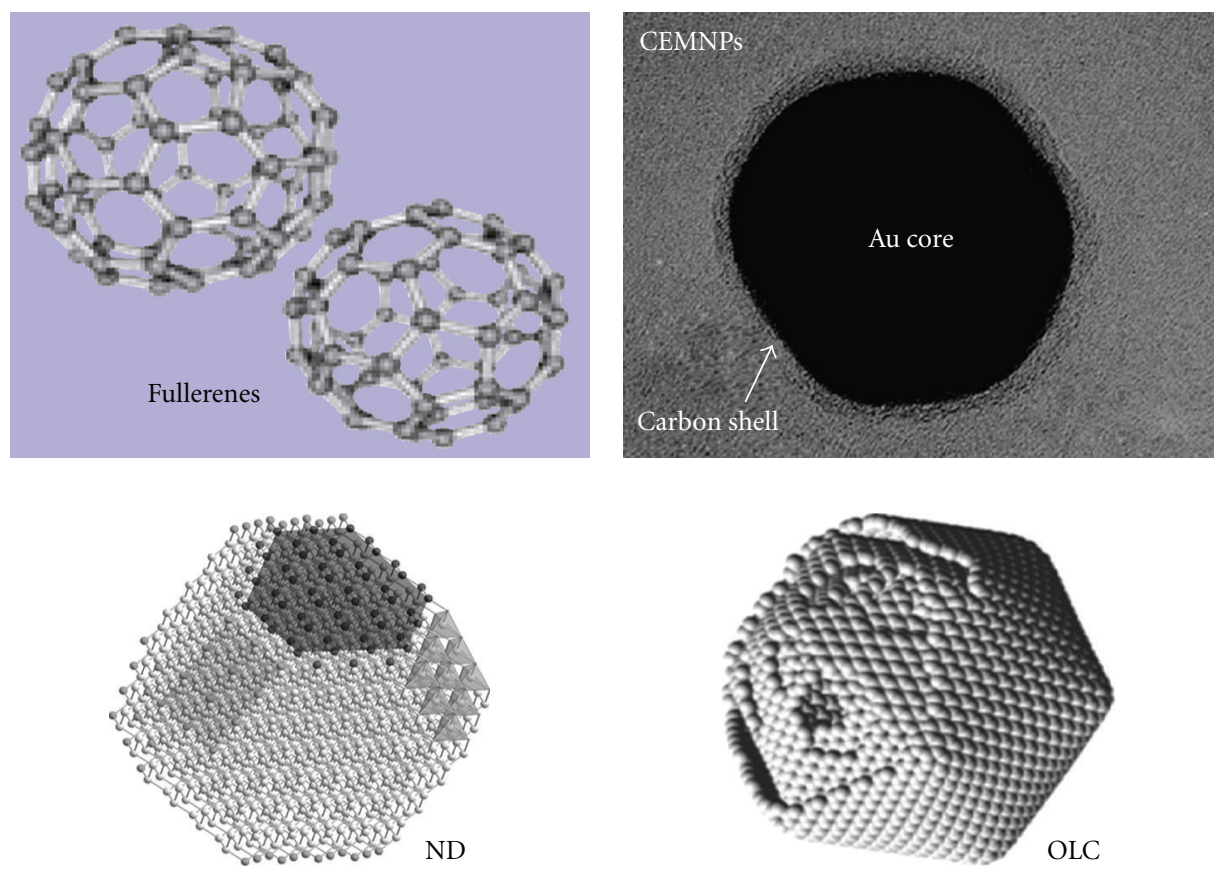

(a)
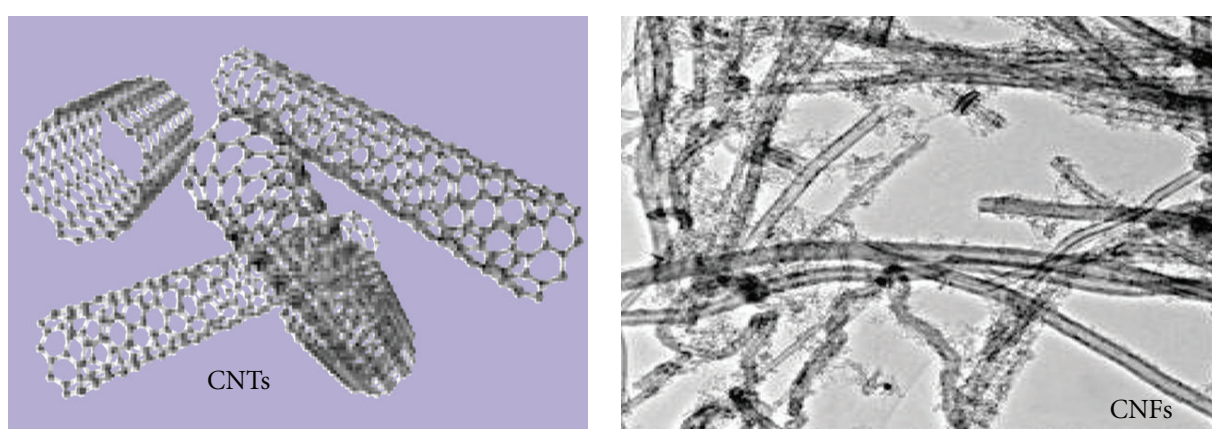

(b)
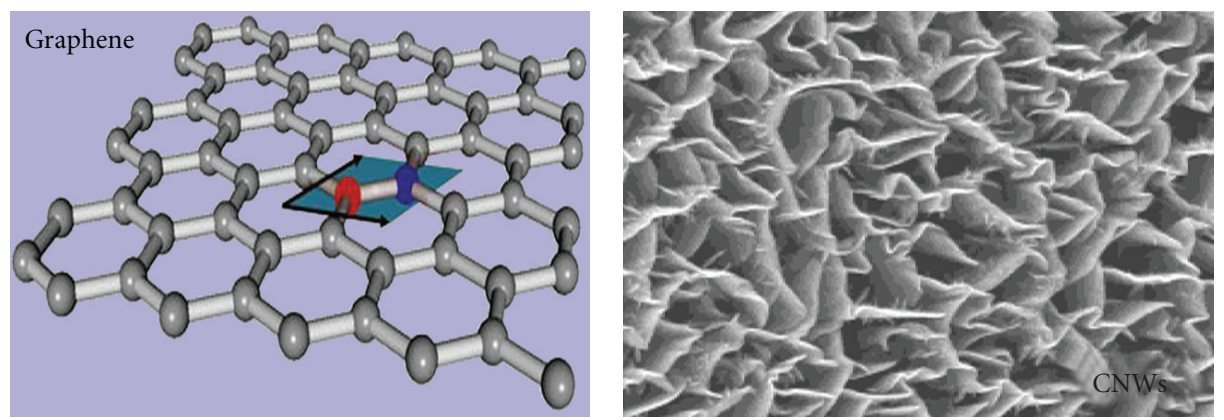

(c)

Figure 1: Crystal structures of the different low-dimensional nanocarbon. From left to right: (a) Fullerene, Carbon-encapsulated metal nanoparticles, Nanodiamond, and Onion-like carbon, (0-D); (b) carbon nanotube and carbon nanofibers, (1-D); (c) graphene and carbon nanowalls, (2-D) [6-11].

cage by arc discharge method. Saito [26] reported that 13 rare earth metals and iron-group metals were wrapped in graphitic carbon in 1995. Dravid et al. [27] solved the major problem about the production of large amounts of unwanted carbonaceous debris in the standard arc method with the synthesis of graphite-encapsulated nanocrystals.
They used tungsten arc technique which lowers the amount of carbonaceous debris produced by lowering the carbon content of the arc. Host et al. [28] also reported the structure and magnetic studies of carbon-coated nanocrystals of nickel and cobalt synthesized in a special low carbon to metal ratio arc chamber using tungsten arc techniques. Host et 


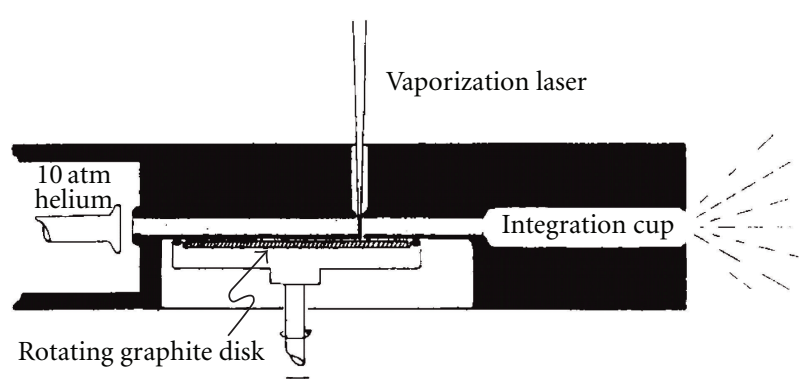

Figure 2: The schematic diagram of fullerene fabrication system using laser vaporization [4].

al. in 1998 [28] and Jiao et al. in 1996 and 1998 [29, 30] reported that a set of carbon encapsulated $\mathrm{Ni}, \mathrm{Co}, \mathrm{Cu}$, and $\mathrm{Ti}$ particles were prepared by an arc discharge process modified in the geometry of the anode and the flow pattern of helium gas. However, the traditional method requires an expensive vacuum system to generate the arc plasma, and the carbon-encapsulated nanoparticles are only found in the soot deposited on the cathode. In 2004, Qiu and Tsang [31] reported the preparation of carbon-coated nickel metal nanoparticles using the arcing coal-based carbon rods submerged in deionized water. The coal-based carbon rods were prepared from a mixture of coal and nickel powders, and the arc discharge was carried out in water instead of in inert gases. The mentioned method resolved a variety of the previous problems.

In 1998, Harris and Tsang [32] described a new technique for carrying out the high-temperature heat treatments on microporous carbons used to encapsulate molybdenum, uranium, and cobalt. The method based on their researches solved the difficulties with the scaleup of low yield. In 2002, Flahaut et al. [33] reported cobalt nanoparticles encapsulated in graphitized carbon shells synthesized using catalytic chemical vapor deposition (CCVD) in high yield involving the reduction by an $\mathrm{H}_{2} / \mathrm{CH}_{4}$ mixture of an $\mathrm{Mg} 1$ $\mathrm{xCoxO}$ solid solution prepared by the combustion method. In 2003, during the researches made by Wang et al. [34], carbon-coated cobalt nanocapsules were synthesized by the chemical vapor-condensation process with cobalt carbonyl $(\mathrm{Co}(\mathrm{CO}))$ used as a precursor and carbon monoxide $(\mathrm{CO})$ as a carrier gas. Tsai et al. [35] reported that a method using microwave plasma enhanced chemical vapor deposition (MPECVD) system to synthesize pure carbon-encapsulated metal nanoparticles on silicon wafer without the existence of other carbon nanostructures.

Liu et al. demonstrated in their paper [36] that carbonencapsulated cobalt nanoparticles were synthesized via the modified catalytic pyrolysis, the mechanical milling derived $\mathrm{Co} / \mathrm{NaCl}$ as catalyst, and the productivity was almost $100 \%$. This method is superior to early catalytic methods in high productivity and is fully separated from the supporting materials by simple washing process, especially the byproducts carbon nanotubes (CNTs) [37].

In 2005, Lu et al. [38] reported the synthesis of carbonencapsulated Fe nanoparticles via a picric acid-detonationinduced pyrolysis of ferrocene. Their technique was a self-heating and extremely fast process. Wu et al. [39] reported a novel method for the synthesis of amorphous carbon-encapsulated $\mathrm{Fe}_{7} \mathrm{C}_{3}$ nanocrystals via the explosion of a hybrid xerogel containing oxidized pitch and iron nitrate. Wang et al. [40] reported a continuous synthesis of high purity, high coercive force and good ferromagnetism CEMNPs based on the spray pyrolysis of a mixture of iron carbonyl and alcohol at $500-900^{\circ} \mathrm{C}$. The technique based on spray pyrolysis offers a large-scale production, the simplicity of the apparatus, and good productivity. Song et al. [41] proposed that the similar carbon-encapsulated $\mathrm{Fe}_{3} \mathrm{C}$ nanoparticles can be synthesized on a large scale via the cocarbonization of 1, 2, 4, 5-tetramethylbenzene and ferrocene under autogenous pressure. Huo et al. [42] synthesized Carbon-encapsulated iron nanoparticles with uniform diameters by cocarbonization of an aromatic heavy oil and ferrocene at $480^{\circ} \mathrm{C}$ under autogenous pressure. This preparation method of CEMNs is characterized by simplicity, low cost, controllability, and high yields. Bystrzejewski et al. [43] synthesized $\mathrm{Fe}, \mathrm{Fe}_{3} \mathrm{C}$, and $\mathrm{NdC}_{2}$ carbon-encapsulated magnetic nanoparticles using thermal radio frequency (RF) plasma torch technique. In that paper, authors found the nonlinear transmission behavior in CEMNPs material with the smallest saturation.

In 2008, Park et al. [44] reported a method (pulsed laser irradiation synthesis, PLIS) to synthesize CEMNPs such as $\mathrm{Fe}-\mathrm{C}, \mathrm{Ni}-\mathrm{C}$, and $\mathrm{Co}-\mathrm{C}$ by irradiating nanosecond laser pulses into a metalocene-xylene solution under room temperature and atmospheric pressure. There will be more CEMNP synthesis arising, because the PLIS method is simple and can be operated under ambient conditions. In 2006, Nishijo et al. [45] synthesized the carbon-encapsulated nanoparticles via thermal decomposition of metal acetylide at a low temperature. Using this method, nanoparticles of low-melting point $\mathrm{Sn}$ and metastable carbide phases of $\mathrm{Pd}$, $\mathrm{Ni}$, and Co were successfully encapsulated in amorphous carbon shells owing to the low synthesis temperature. Recently, Maya et al. [46] have produced and characterized encapsulated silver nanoparticles provided by high-current pulsed electric arcs system in an argon atmosphere. The main advantage of this method is that the metal nanoparticles are encapsulated in amorphous carbon from the beginning, and this layer acts as an efficient chemical barrier.

In summary, as briefed in Table 1, CEMNPs can be synthesized by a variety of techniques such as arc discharge method, tungsten arc techniques, high-temperature heat treatments, the mechanical milling, cocarbonization, pulsed laser irradiation, and high-current pulsed electric arcs system.

2.1.3. Nanodiamond (ND). As we all know, diamond is one of the carbon allotropes as graphite. Graphite is the most stable form of carbon at ambient pressure. Spherical and truncated octahedron diamond with predominant sp3bonded carbon is one of the hardest materials known to date and is often regarded as the king of all gemstone and topdrawer materials because of its excellent scientific qualities in hardness, chemical corrosiveness, thermal expansion and conductivity, electrical insulation, and biocompatibility. On 
the other hand, nanodiamond (ND) is a cubic structural diamond. It possesses diamond structure and diamond properties. The average size is mere $5 \mathrm{~nm}$ in diameter. In the wide sense of the word, "nanodiamond" contains a variety of diamond-based materials at the nanoscale (the length scale of approximately $1-100 \mathrm{~nm}$ ) including pure-phase diamond films, diamond particles, and their structural assemblies. Several synthesis methods have been developed to synthesize laboratory-produced nanodiamonds. There are two main methods for fabrication of nanodiamond: transformation of graphite under high temperature and high pressure and detonation of the carbon explosive materials.

In 1955, Bundy et al. [47] realized the 30-year dream of many scientists in which diamond can be transformed from graphite. Under the title "Man-made diamonds" in Nature [47], Bundy and his coworkers successfully reported the synthesis of diamond using a high-temperature and highpressure process. However, the synthesis of diamond by the detonation of explosives with a negative oxygen balance in a steel container under vacuum condition was reported in the 1980s $[48,49]$. There are also some related literatures in recent reports shown two mentioned methods [5055]. Explosive detonation is still widely used; however, the process of the detonator explosion is extremely fast and very complex. Moreover, there are some disadvantages observed in detonation method. In fact, the fraction of surface to bulk atom and oxygen, hydrogen, and nitrogen content in the nanodiamond resulting from after- purification process are difficult to remove.

As an interesting matter, most previous researches on detonation synthesis have been done at military or commercial plants; thus several reports are available for the scientific community. Therefore, the best method is to develop new techniques to the synthesis of well-dispersed and pure nanodiamonds. Recently, more researches also about the aspects of low energy, low cost, easily controlled, few byproducts, controlled-sized, and large scale have been reported in related literatures, such as microwave plasma chemical vapor deposition [56-58], hot filament chemical vapor deposition [59], pulse laser ablation [60-62], electron irradiation [63], and high-energy X-ray diffraction [64].

2.1.4. Onion-Like Carbons (OLCs). Ugarte [65] in 1992 reported that carbon soot particles and tubular graphitic structures were radiated by intense electron-beam and reorganized into quasispherical particles. Subsequently, Harris and Tsang [66] in 1997 studied the structure of two typical nongraphitizing carbons by heat treatment. They observed the fullerene-like structure close to carbon nanoparticles. Then, a new model for nongraphitizing carbons was proposed which was different with the other representatives of the carbon family graphite, fullerenes, and nanotubes. The onion-like carbons (OLCs) have the three to eight closed graphitic shell structures with the hollow core. The outer diameters are in the range of $20-100 \mathrm{~nm}$. The polyhedral nanoparticles exhibited a well aligned concentric and high degree of symmetry structure. Quasispherical shape, nanometer size, and surface specificity of OLCs have attracted enormous attention. Several routes were developed from synthesis of carbon onions including arc discharge $[67,68]$, high-electron irradiation [69], chemical vapor deposition [70], radio frequency plasma [71] and highdose carbon ion implantation into metals [72], and [73, 74] thermal annealing of diamond nanoparticles [75].

The current researches on OLCs are limited because of unmanageable reaction, many byproducts, complex equipments, and high cost. Extensive research has been devoted to search the optimal synthetical route. At present, the most OLCs were synthesized using vacuum annealing of nanodiamond particles at fixed temperatures [75]. For instance, in 2007, Bulusheva et al. [76] produced quasispherical and polyhedral OLCs using vacuum annealing of nanodiamond (ND) particles, and the first researched quantum chemistry characterization and the electronic structure of OLCs by Xray absorption spectroscopy. Recently, in 2010, Bystrzejewsk et al. [77] described a simple, facile, and low-cost process of the synthesis of OLCs by a catalyst-free $\left(\mathrm{NaN}_{3}-\mathrm{C}_{6} \mathrm{Cl}_{6}\right.$ mixture) thermolysis route, and meanwhile, this method solved the problem of separation.

Zhao et al. [78] reported a large quantities synthesis of OLCs using carbonization of the solid-state catalyst of $\mathrm{PF}$ resin as the carbon resource and ferric nitrate as the precursor at $1000^{\circ} \mathrm{C}$. Liu et al. [79] also synthesized OLCs using $\mathrm{Fe} / \mathrm{Al}_{2} \mathrm{O}_{3}$ as catalyst by chemical vapor deposition $(\mathrm{CVD})$ at a relatively low temperature $\left(400^{\circ} \mathrm{C}\right)$ and efficiently avoided the growth of CNTs. Du et al. [80] synthesized highpurity OLCs in high yields from coal by radio frequency plasma economically.

\subsection{One-Dimensional Carbon Nanomaterials (1-DCNs)}

2.2.1. Carbon Nanofibers. Carbon nanofibers (CNFs) are composed of stacked and curved graphene layers from a quasi-one-dimensional (1D) filament. CNFs have cylindrical or conical nanostructures. Their diameters vary from a few to hundred nanometers, while lengths range from less than a micrometer to millimeters. As shown in Figure 3, according to the angle between graphene layers and fiber axis, the morphological structure is often divided into plate CNFs, ribbon-like CNFs, herringbone CNFs [81].

CNFs known as filamentous carbon have been known for a long time [82]. However, the synthesis of filamentous carbons did not evoke great interest of scientists in those early years until the discovery of carbon nanotubes by Iijima in 1991 [83]. Generally, CNFs can be synthesized through the traditional vapor growth method [84-86], cocatalyst deoxidization process [84], catalytic combustion technique [85], plasma-enhanced chemical vapor deposition [87, 88], hot filament-assisted sputtering [89], ultrasonic spray pyrolysis [90], and ion beam irradiation [91].

The large-scale production of CNFs has usually been carried out by using PECVD in which CNFs are grown by catalytic decomposition of hydrocarbon under high temperature. Catalytic PECVD provides a means for the controlled synthesis of CNTs and CNFs and grows individual nanostructures with deterministic characteristics by changing the starting materials or plasma conditions during growth. This review will focus on the catalytic PECVD 


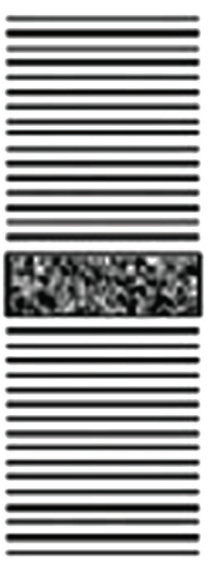

CNF-P

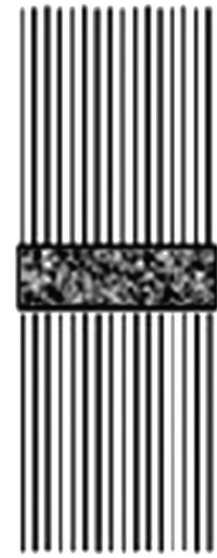

CNF-R

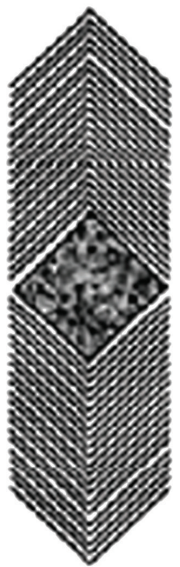

CNF-H
FIGURE 3: The schematic diagram of three different CNFs: platet $\mathrm{CNFs}$ and ribbon-like CNFs, herringbon CNFs [81].

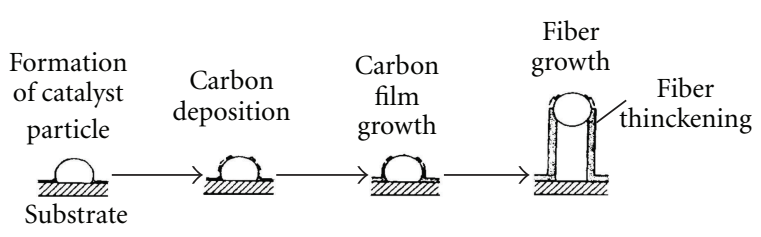

(a)

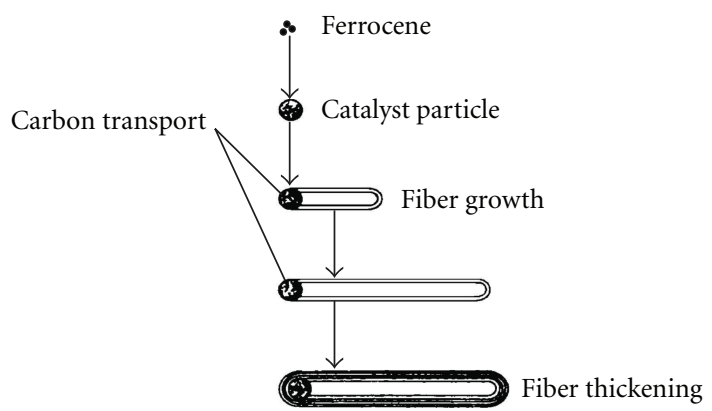

(b)

FIgure 4: Two methods of synthesizing VACNFs: (a), "seeded catalyst on a flat plate" and (b), " floating catalyst" [92].

growth process used to produce vapor grown carbon fibers (VGCFs) as depicted. As shown in Figure 4, there are two methods to synthesize VACNFs. First, the method based on "seeded catalyst on a flat plate" and second, the "floating catalyst method". The first technique uses the catalysts seeded on a substrate within the reactor, while in another method, the catalyst is deposited on a selected substrate as a film by sputtering or evaporation techniques.

Firstly, the commonest way used thin films of $\mathrm{Ni}, \mathrm{Fe}$, or Co metallic catalyst $[93,94]$ or their alloys [95], $\mathrm{Cu}-$ Ni composition [96], nickel-copper-aluminum takovite [97], mixture of $\mathrm{Ni}(\mathrm{OH})_{2}-\mathrm{Mg}(\mathrm{OH})_{2}$ [98], ferrocene [99], copper titrate [100], and cobaltocene [101] as catalyst precursors. Moreover, a buffer-layer such as Ti was often used as a barrier to diffuse and promote particle formation. Secondly, it is a"pretreatment step"; Carrier gas such as ammonia $\left(\mathrm{NH}_{3}\right)$ or hydrogen $\left(\mathrm{H}_{2}\right)$ is introduced as the chamber to a few Torr, and the sample is heated to the desired temperature, usually $500-700^{\circ} \mathrm{C}$. Plasma is then initiated for several seconds to minutes. Lastly, there is the carbon source gas (such as $\mathrm{C}_{2} \mathrm{H}_{6}$ [102], $\mathrm{C}_{2} \mathrm{H}_{5} \mathrm{OC}_{2} \mathrm{H}_{5}$ [103], $\mathrm{C}_{2} \mathrm{H}_{2}$ [104], C60 [105]) in the plasma, which immediately initiates CNF growth. The later way uses the catalysts and the carbon source gas floating in the reactor space at the same time.

This paper focuses mainly on the PECVD technique from the aspects of metal catalyst, carbon source, processing method, and other techniques by virtue of the classical examples and the recent reports. Pham-Huu et al. [102] showed that large-scale and uniform carbon nanofibers with a diameter of about $50 \mathrm{~nm}$ can be synthesized using the catalytic decomposition of a mixture of ethane and hydrogen over a nickel catalyst decorating carbon nanotubes at 550$650^{\circ} \mathrm{C}$. The attained CNFs need not subsequent purification, due to the use of carbon nanotubes as support, the high nanofiber yields, and the purity reached. Zou et al. [103] reported that CNFs were prepared by cocatalyst $\mathrm{Zn}$ and $\mathrm{Fe}$ powders deoxidization process using $\mathrm{C}_{2} \mathrm{H}_{5} \mathrm{OC}_{2} \mathrm{H}_{5}$ as starting material at $650^{\circ} \mathrm{C}$. The obtained nanofibers possessed diameters about $80 \mathrm{~nm}$, lengths ranging from several micrometers to tens of micrometers, low graphitic crystalline, and good electrochemical properties. The cocatalyst synergetic effect is valuable in controlling the resultant nanofiber diameter for synthesis and the study of other carbonous materials. Yu et al. [104] synthesized carbon nanofibers using the thermal decomposition of acetylene by a copper nanocatalyst derived from cupric nitrate trihydrate at a low temperature of $260^{\circ} \mathrm{C}$. The copper nanoparticle size has a considerable effect on the morphology of carbon nanofibers. Helical carbon nanofibers and straight carbon nanofibers laid on catalyst copper nanoparticles with a grain size less than $50 \mathrm{~nm}$ or within $50-200 \mathrm{~nm}$. The present study further assumes that it is possible to control the diameter of CNFs by controlling the size of the catalyst particle. Zhang et al. [105] successfully prepared carbon nanofibers with a diameter of about $100 \sim$ $500 \mathrm{~nm}$ using C60, graphite-carbon, and boron powders via the ultrasonic spray pyrolysis method of ethanol without using metal catalysts. The experiment indicates that the clusters composed of carbon- and boron-related materials act as nucleating sites for CNFs formation. Kimura et al. [106] synthesized CNFs (lengths of $1-20 \mu \mathrm{m}$, uniform diameters of $20-100 \mathrm{~nm}$ ) with high electrical conductivity by ion beam irradiation of decacyclene whiskers at ambient temperature. This novel method of preparation without catalyst is advantageous for aligning the fibers as desired. The mechanisms of CNFs formation were shown in detail and found that CNFs were not grown from the film but were generated by the conversion of pre-existing whiskers of decacyclene on the film. Matsumoto et al. [107] described that carbon nanofibers were obtained using a hot filamentassisted sputtering system with pure argon gas as the sputtering gas, with a tungsten hot filament as the thermal electron emission source. Gulás et al. [108] observed that CNFs and related structures with outer diameters $20-60 \mathrm{~nm}$ were prepared by combination of aerosol synthesis and plasma-enhanced catalytic chemical vapor deposition with 
alcohol as carbon precursor catalytic CVD (PE CCVD). $\mathrm{Al}_{2} \mathrm{O}_{3}$ and $\mathrm{Si}$ coated $\mathrm{Fe}$ and $\mathrm{Ni}$ were deposited as catalysts. Ethanol and isopropyl alcohol vapors were used as a carbon source. HCGD is used as a gas activation process without any specific heating of the substrate that plays an important role in gas decomposition and activation for CNFs growth. On the other hand, Ren et al. [109] reported a simple synthesis method of carbon nanofibers using combustion of ethyl alcohol. Copper plate was employed as substrate, iron nitrate, and iron chloride as catalyst precursor and ethanol as carbon source. Carbon nanofibers with diameters of $10-100 \mathrm{~nm}$ were produced in bulk by the floating catalyst method by $\mathrm{Ci}$ et al. [110]. Several experiments showed the growth of carbon fibers depending on the reactor conditions and experimental parameters, so it was easily controlled to synthesize the large scale of carbon nanofibers. Mori and Suzuki [111] demonstrated that vertically aligned freestanding CNFs can be synthesized at low temperature as low as $90^{\circ} \mathrm{C}$ by plasma-enhanced chemical vapor deposition at low temperature $\mathrm{CO} / \mathrm{Ar} \mathrm{DC}$ plasma. The low-temperature synthesis of carbon nanofibers was demonstrated that the addition of a small amount of $\mathrm{O}_{2}$ was favorable for the synthesis of CNFs, because it suppresses the deposition of amorphous carbon.

2.2.2. Carbon Nanotubes. Carbon nanotubes are rolledup into tubular structures by sp2-bonded graphite sheets with nanometer diameter and large length ratio. The nanotubes may consist of two different types of carbon nanotubes. Namely, singlewall nanotubes (SWNTs) made of single layers of graphene cylinders with typical diameter of the order of $1.4 \mathrm{~nm}$ and the multiwall nanotubes (MWNTs) made of 4-24 concentric cylinders of graphene layers with adjacent shells separation of $0.34 \mathrm{~nm}$ and a diameter typically of the order $10-20 \mathrm{~nm}$. Nowadays, carbon nanotubes are still mainly synthesized by the arc-discharge, laser-ablation (vaporization), and chemical vapor decomposition (CVD) method.

The MWNTs were first observed which deposited on the negative electrode during the direct current arc-discharge of two graphite electrodes for preparation of fullerenes in an argon-filled vessel by Iijima in 1991 [112]. Large-scale and high-quality MWNTs were achieved by arc-discharge technique first by Ebbesen and Ajayan in 1992 [113]. In 1993, singlewall carbon nanotubes (SWNTs) are almost simultaneously obtained by arc-discharge and catalyst-assited arcdischarge by Iijima and Ichihashi [114] and Bethune et al. [115]. Iijima and Ichihashi [114] used arc-discharge chamber that installed two vertical thin electrodes with a small piece of iron filled with a gas mixture of methane and argon. On the other hand, Bethune et al. [115] reported that SWNTs can be obtained by arc-discharge of anode thin electrodes with bored holes powdered metal catalysts $(\mathrm{Fe}, \mathrm{Ni}$ or $\mathrm{Co}$ ) incorporated into anode. As the arc method, metal catalysts were needed for the growth of SWNTs in contrary to MWNTs. Journet et al. [116] obtained large quantities of SWNTs by arc-discharge using a carbon anode with yttrium and nickel as catalysts. In 1996, high-yield SWNTs were produced using laser-ablation method of graphite with $\mathrm{Ni}$ and Co catalysts at

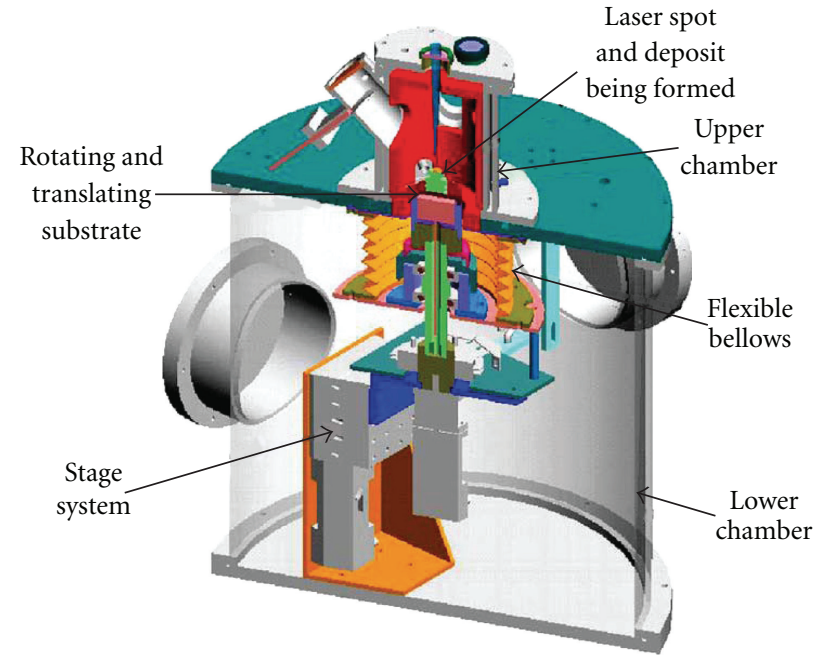

FIGURE 5: The schematic diagram of CNTs fabrication using the laser CVD reactor [129].

$1200^{\circ} \mathrm{C}$ by Thess et al. [117]. The techniques based on arcdischarge and laser-ablation both have the advantage of high yield but also face the problem of high temperature needed and impurity. The chemical vapor deposition has been used successfully for producing carbon fiber and filament since the 1960s. Yacaman et al. [118] first produced the MWNTs by chemical vapor decomposition method in 1993. Flahaut et al. [119] made bulk amounts of SWNTs using CVD of methane catalysted on mixed oxide spinels. When using CVD for synthesized CNTs, catalysts brought high yield because the increased metal-supporting interactions were propitious to the growth of carbon nanotube, which also caused impurity and aggregation of the metal nanoparticles. A diagram of CNTs fabrication by the method of CVD is schematically shown in Figure 5. Vast amount of reviews on carbon nanotubes have been discussed in the recent literature in detail, including the synthesis and growth mechanisms of CNT [120-129]; therefore, we described only three main productions in brief.

\subsection{Two-Dimensional Carbon Nanomaterials (2-DCNs)}

2.3.1. Graphene. Graphene, one-atom-thick planar sheet of $\mathrm{sp}^{2}$-bonded carbon atoms, is arranged densely in a twodimensional hexagonal honeycomb crystal lattice. There are three extremely strong $\sigma$ bonds in-plane result in the mechanical stability of the carbon sheet, $\pi$ orbitals perpendicular to the plane interactions between graphene and a substrate or between graphene layers are responsible for the electron conduction. It is the basic building block of (0-D) fullerenes, (1-D) carbon nanotubes, and (3-D) graphite.

In a large scientific community, more allotropes of carbon have been reported in succession. Diamond and graphit have been known for centuries, and the recently discovered fullerenes and nanotubes also have been studied in the last two decades. For a long time, graphene was 
only considered as theoretical concept. Until 2004, [130] a physicists group led by Andre Geim and Kostya Novoselov from Manchester University, UK used mechanical exfoliation approach to obtain graphene. The discovery of isolated graphene monolayer has attracted wide attention to investigate the properties of this new yet ancient two-dimensional carbon nanomaterial due to its exceptional electronic and mechanical properties. More and more simple methods were searched for the growth of graphene. Several typical methods have been developed and reviewed as follows.

Mechanical Exfoliation. As mentioned above, [130] graphene flakes were first produced by continuously cleaving a bulk graphite crystal with a common adhesive tape and then transferred the thinned down graphite onto a cleaned oxidized silicon wafer substrate with visible color. The technique started with three-dimensional graphite and extracted a single sheet (a monolayer of atoms) called mechanical exfoliation or micromechanical cleavage.

Until now, mechanical exfoliation of graphite is still the best method to provide a small amount of highquality samples for the study of a variety of graphene properties. Furthermore, the venerable technique has been used easily to obtain large size (up to $100 \mu \mathrm{m}$ ), highquality, two-dimensional graphene crystallites, which immediately brought enormous experimental researches [131134]. Meanwhile, modified techniques are needed to provide a high yield of graphene for industrial production.

Epitaxial Growth. Recently, graphene was obtained by the epitaxial growth of graphene layers on metal carbides using thermal desorption of metal atoms from the carbides surface, or directly on metal surfaces by chemical vapor deposition (CVD). The typical carbide is SiC; silicon carbide heated to very high temperatures leads to evaporation of $\mathrm{Si}$ and the reformation of graphite; the control of sublimation results in a very thin graphene coatings over the entire surface of $\mathrm{SiC}$ wafers, which initially showed more performances than devices made from exfoliated graphene. So far, all of known synthesis approaches, however, are required in specialized laboratories for graphene sheets whose electronic properties are often altered by interactions with substrate materials. The development of graphene required an economical fabrication method compatible with mass production. The latest modified method was demonstrated by Aristov et al. [135]. Based on their work, for the first time, graphene was synthesized commercially on available cubic $\beta$-SiC/Si substrates, which was a simple and cheap procedure to obtain industrial mass production graphene, which meets the need of technological application. Moreover, many other types of carbide have been exploited to produce supported graphene, such as $\mathrm{TiC}(111), \mathrm{TiC}$ (410), and $\mathrm{TaC}(111)$. It is well proved that metal surfaces can efficiently catalyze decomposition of hydrocarbons into graphitic materials to support growth of graphene on metallic surfaces by CVD. The advantage of epitaxial growth is large-scale area, but it is difficult to control morphology, adsorption energy, and high-temperature process.
Chemical Exfoliation. The theory of chemical exfoliation is to insert reactants in the interlayer space for weakening the van der Waals cohesion. At first, the graphite flakes are forced upon oxidative intercalation of potassium chlorate in concentrated sulphuric and nitric acid, received carbon sheets with hydroxyl and carboxyl moieties. The suspension is known as graphite oxide (GO). The GO is highly dispersible in water, and it can be easily deposited onto $\mathrm{SiO}_{2}$ substrates. The precipitate of GO is sonicated to form separated graphene oxide sheet, then another reduction, and finally graphene sheet is formed. When $\mathrm{KClO}_{3}$ is used, it generates a lot of chlorine dioxide gas and emits a great deal of heat, so the mixture is highly hazardous [136]. In 1958, Hummers and Offeman [136] reported a modified method which was much faster and safer. Based on the technique introduced by them, graphite is dispersed into a mixture of concentrated sulfuric acid, sodium nitrate, and potassium permanganate in contrast to $\mathrm{KClO}_{3}$ [137]. Meanwhile, it must use $\mathrm{H}_{2} \mathrm{O}_{2}$ to eliminate the $\mathrm{MnO}_{2}$ generated from $\mathrm{KMnO}_{4}$ time after time. This process faced a similar situation when it used m-CPBA [138] as an oxidant. Chandra et al. [139] also reported a novel synthetic route using oxidation acidified dichromate, to get high quality and stable aqueous dispersed graphene sheets. After GOs were deposited, chemical reduction of GO was accompanied by the elimination of epoxy and carboxyl groups using different reductants such as hydrazine [140], dimethylhydrazine [141], hydroquinone [142], and $\mathrm{NaBH}_{4}$ [143], under alkaline conditions [144] or with thermal methods [145]. Because the reductants are usually hazardous, there are lots of interests on green routes to speed deoxygenation of graphene oxide. Wakeland et al. [146] introduced an approach to synthesize graphene from GO using urea as expansion reducing agent heated in an inert gas environment $\left(\mathrm{N}_{2}\right)$ for a very short time to a moderate temperature $\left(600^{\circ} \mathrm{C}\right)$. Chen et al. [147] successfully achieved thermal reduction of graphene oxide (GO) to graphene with the assistance of microwaves in a mixed solution of $\mathrm{N}, \mathrm{N}$ dimethylacetamide, and water $\left(\mathrm{DMAc} / \mathrm{H}_{2} \mathrm{O}\right)$. The reduction of GO can be accomplished rapidly and mildly. This method is rapid, not requiring any solvents or stabilizers, inexpensive, and easy to scale up.

2.3.2. Carbon Nanowalls. Carbon nanowalls (CNWs) consist of vertical aligned graphene sheets standing on the substrates, form two-dimensional wall structure with large surface areas and sharp edges. The thickness of CNWs ranges from a few $\mathrm{nm}$ to a few tens nm. So far, research groups have explored different synthesis methods of CNWs based on plasma-enhanced chemical vapor deposition techniques. The main approaches are as follows.

(1) Microwave plasma-enhanced chemical vapor deposition (MWPECVD).

(2) Radio-frequency plasma-enhanced chemical vapor deposition (RFPECVD) (RF inductively coupled plasma (ICP) and RF capacitively coupled plasma (CCP)).

(3) Hot-wire chemical vapor deposition (HWCVD). 
(4) Electron beam excited plasma-enhanced chemical vapor deposition (EBEPECVD).

For the first time, carbon nanowalls were accidentally discovered during the growth of carbon nanotubes by $\mathrm{Wu}$ et al. [148] using MWPECVD. In the experiment, the NiFecatalyzed substrate $\left(\mathrm{Si}, \mathrm{SiO}_{2} / \mathrm{Si}\right.$, sapphire) was preheated to about $650-700^{\circ} \mathrm{C}$ in hydrogen plasma; the mixtures of $\mathrm{CH}_{4}$ and $\mathrm{H}_{2}$ were utilized as flow gases. The nanowalls were monitored using SEM in different growth stages. The wellcontrolled MWPECVD synthesis process induced further studies to search more flexible control of the growth of CNWs, which aided to understand the mechanisms of CNWs growth and solving unwanted byproduct owing to the use of metal catalyst particles.

Recently, some groups have prepared CNWs without catalysts, using RFPECVD, assisted by a hydrogen atom injection. Shiji et al. $[149,150]$ synthesized carbon nanowalls on a $\mathrm{Si}$ substrate without catalysts using capacitively coupled RFPECVD by $\mathrm{H}$ atom injection. The grown samples employed fluorocarbon/hydrogen mixtures, used $\mathrm{C}_{2} \mathrm{~F}_{6}, \mathrm{CF}_{4}$, $\mathrm{CH}_{4}$, and $\mathrm{CHF}_{3}$ as the carbon source gas, and heated a substrate temperature of $500^{\circ} \mathrm{C}$. The SEM images monitored the grow of carbon nanowalls using different system and the vacuum ultraviolet absorption spectroscopy (VUVAS) measured $\mathrm{H}$ atom density in the plasma in order to discuss the growth mechanism of carbon nanowalls. The experiment demonstrated that the structure and growth rate of carbon nanowalls depended on the types of carbon source gases and $\mathrm{H}$ atoms and played an important role for the formation of carbon nanowalls.

Considering the practical applications of carbon nanowalls, large scales of CNWs using MWPECVD and RFPECVD are difficult to provide. A promising method such as HWCVD enables to access the large scales easily compared with the above two methods. Moreover, HWCVD/ CAT-CVD have the additional advantage of a high-hydrogen radical density.

Itoh et al. [151] reported that CNW films have been successfully prepared using only $\mathrm{CH}_{4}$ by HWCVD. In the growth of CNWs, a substrate heated over $500^{\circ} \mathrm{C}$ would be needed. The hydrogen $\mathrm{H}_{2}$ pressure is of $133 \mathrm{~Pa}$ by radical treatment. The structure of the CNWs has been studied by scanning electron microscope (SEM) and Raman spectroscopy. There are two reports about CNWs synthesis using $\mathrm{CH}_{4}$ with different hydrogen dilution [152] and without hydrogen dilution [151] by HWCVD. Furthermore, Mori et al. [153] studied fabrication of vertically aligned and definite CNWs by an EBEPECVD employing a mixture of $\mathrm{CH}_{4}$ and $\mathrm{H}_{2}$ at relatively low temperature of $570^{\circ} \mathrm{C}$. Figure 6 shows a schematic diagram of CNWs fabrication using EBEPECVD. An EBEP is a high-density plasma directly obtained by a high-current and low-energy electron beam. CNWs were characterized using SEM, TEM, and MRS [153].

According to the recent progress report [154], carbon nanowalls with large-surface areas and sharp edges were obtained on nickel-coated oxidized silicon substrates by PECVD in a radiofrequency Ar plasma beam injected with acetylene at temperature of $600^{\circ} \mathrm{C}$. The formation of carbon nanowalls was proved by SEM, TEM, ED, and Raman spectra. The mentioned study showed that the shape, surface distribution, and size of the nanostructures depended on the nature of the active gas and on the gas mass flow ratio in the $\mathrm{Ar} / \mathrm{H}_{2} / \mathrm{C}_{2} \mathrm{H}_{2}$ mixture.

Different from previous reports, various growth mechanisms and deposition parameters (catalyst, the effect of localized plasma) of CNWs were explored on a flat substrate, where existed a different growth mechanism. Non-surfacebound (freestanding) growth of CNWs by the method of MWPECVD without using the metal catalyst under a gas mixture of $\mathrm{C}_{2} \mathrm{H}_{2}$ and $\mathrm{NH}_{3}$ was developed by Chuang et al. [155]. A growth stage was used to facilitate energy-intensive, localized plasma for the growth of carbon nanowalls. Owing to the freestanding nature of their growth and the absence of catalyst, the synthesis process easily obtains a large scale of carbon nanowalls without impurity by metal catalyst particles and processed for various applications. There is a similar report [156] of freestanding graphite sheets with thickness less than $1 \mathrm{~nm}$, in which "carbon nanosheets" were synthesized on a variety of substrates by RFPECVD without any catalyst or special substrate treatment. Further studies will be required to understand the formation of non-surfacebound (freestanding) carbon nanowall materials.

Sato et al. [157] investigated the density peak in argon plasma and found that the helicon wave was effectively excitated and produced the plasma antenna. For the first time, the helicon-wave discharge was demonstrated to be used as PECVD source for the growth of CNWs. Using the helicon-wave reactive plasma as a precursor source for plasma-enhanced chemical vapor deposition, well-aligned carbon nanowalls are found to be formed even in a very low gas pressure of $0.7 \mathrm{~Pa}$. Table 1 briefs the main synthesis methods of different low-dimensional carbon nanomaterials as described in this section. Further development in this field is expected on their rich physics and potential applications.

\section{Properties and Applications}

There are several various allotropes of carbon such as graphite, diamond, and amorphous carbon. Therefore, the physical and mechanical properties of carbon strongly depended on the allotropic forms of carbon. As an example for the mechanical property of hardness, diamond is known as one of the hardest materials, while graphite is soft enough to be used for making pencils. About the property of color, diamond is considered transparent while graphite is an opaque material and black. As another example, while graphite is a good conductor, diamond just demonstrates a low electrical conductivity. On the other hand, diamond is normally known as a highly thermal conductive, while graphite is considered as the most thermodynamically stable material.

3.1. Fullerene. As described in Section 2.1.1, fullerene belongs to zero-dimensional carbon nanomaterials. Applications of fullerene include the applications in medicine such as their aid to produce the specific antibiotics and drugs for 


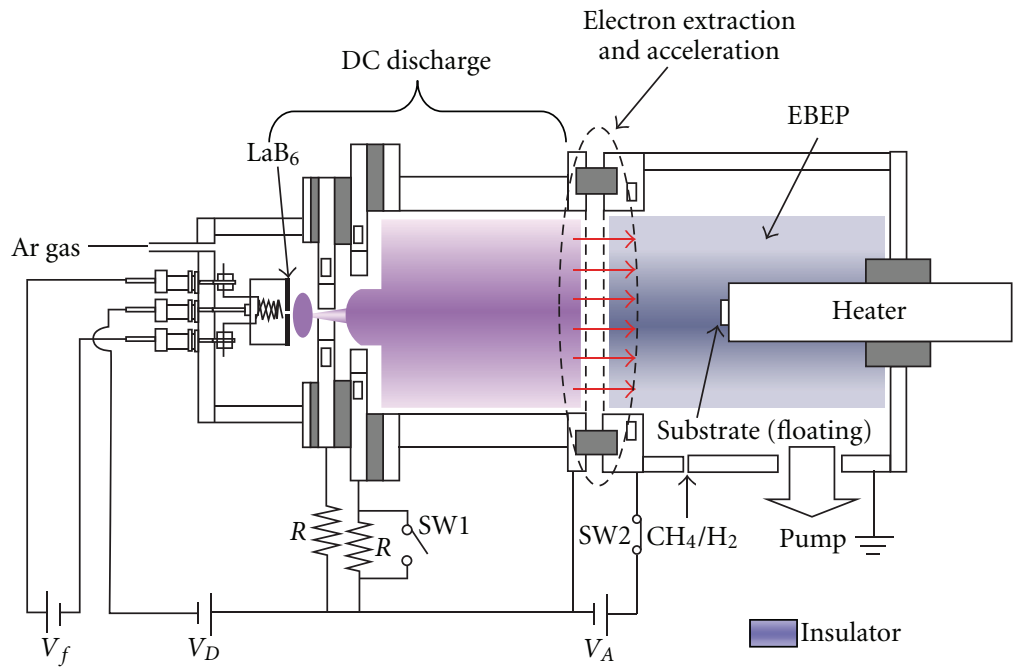

FIgure 6: The schematic diagram of CNWs fabrication using EBEPECVD [153].

TABLE 1: Comparison of the main synthesis methods of different low-dimensional carbon nanomaterials.

\begin{tabular}{ll}
\hline LDC-nanomaterial & Synthesis methods \\
\hline Fullerene & Laser vaporization, Arc discharge, Combustion, Microwave plasma Pyrolysis, Flat flames \\
CEMNPs & Arc-discharge, high-temperature heat treatment, mechanical milling, Co-carbonization, Pulse-laser irradiation \\
ND & MPCVD, Hot-filament, CVD, Pulse laser ablation, Electro irradiation, High-energy X-ray diffraction \\
OLCs & Arc-discharge, High-electron irradiation, CVD, RFP Thermal annealing of diamond nano-particle \\
CNFs & Traditional vapor growth, Catalytic combustion, PECVD, Hot filament-assisted sputtering, Ultrasonic spray \\
CNTs & pyrolysis, Ion beam \\
Graphene & Arc-discharge, Laser-ablation, CVD, Other methods \\
CNWs & Mechanical exfoliation, Epitaxial growth, Chemical exfoliation \\
\hline
\end{tabular}

certain cancers particularly melanoma. On the other hand, due to their specific properties, fullerenes have had great applications in the field of superconductivity.

In 1991, Haddon et al. [158] reported the preparation of alkali-metal-doped films of C60 and C70 which have electrical conductivities at room temperature that are comparable to those attained by n-type-doped polyacetylene. They observed the highest conductivities in the doped films equal to $4 \mathrm{Scm}^{-1}$ (Cs/C60), 100 (Rb/C60), 500 (K/C60), 20 (Na/C60), 10 (Li/C60), and 2 (K/C70) [152]. In the same year, Hebard et al. [159] reported that potassium-doped C60 becomes superconducting at $18 \mathrm{~K}$ [159]. As the researchers stated in their paper [159], the observed superconductivity at $18 \mathrm{~K}$ was the highest yet observed for a molecular superconductor. Furthermore, the superconductivity in fullerene doped with various other alkali metals was reported by some other researchers [160, 161]. Subsequently, Zhou et al. in 1992 [162] and Brown et al. in 1999 [163] showed that the superconducting transition temperature in alkaline-metaldoped fullerene was elevated while the unit-cell volume $\mathrm{V}$ was increased. In 2008, Ganin et al. [164] reported the bulk superconductivity at $38 \mathrm{~K}$ in a molecular system. The system introduced by the researchers was bulk $\mathrm{Cs}_{3} \mathrm{C}_{60}$ as a key material in this family [164], and as the authors explained, cesium-doped fullerene is an important material in the same family [164].

On the other hand, fullerenes are almost stable chemically, however, not completely uncreative. In the view of the solubility, apart from some fullerene structures which are not soluble due to the presence of a small band gap in their structure between the ground and excited states, they are generally soluble in various solvents. In fact, fullerenes are the only carbon allotropes which can be dissolved in common solvents at room temperature. The mentioned common solvents can be aromatics such as toluene and carbon disulfide.

3.2. Nanodiamond Properties. The physical properties of nanodiamonds (NDs) are briefed in Table 2 [165]. Due to the unique structure of nanodiamonds, they are known as the nanomaterials with significant properties. In fact, 30 percent of nanodiamond atoms are located on the surface of their structure. The maximum size of the single grains of nanodiamonds is $10 \mathrm{~nm}$, while the average particle size is obtained between 4 and $6 \mathrm{~nm}[50,166]$.

In 2000, Iakoubovskii et al. [50] applied the method of X-ray diffraction (XRD) to study the characterization of the structure and defects in detonation synthesis and 
TABLe 2: Physical properties of nanodiamond [165].

\begin{tabular}{lc}
\hline Structure & Cubic $(a=0.3573 \mathrm{~nm})$ \\
\hline Particle size & $4.5 \mathrm{~nm}$ \\
Number of C atoms & ca. 10,000 \\
Molar mass & $120,000 \mathrm{~g}$ \\
Specific surface area & $300 \mathrm{~m}^{2} / \mathrm{g}$ \\
Graphitization temperature & $1100^{\circ} \mathrm{C}$ \\
Zeta potential & $-78.44 \mathrm{mV}$ \\
Refractive index & 2.55 \\
\hline
\end{tabular}

ultradisperse diamond (UDD). In 2008, Iakoubovskii et al. have applied the method based on high-resolution transmission electron microscopy (HRTEM) [166]. They have showed that the surface area of nanodiamond is relatively large, and the size of diamond grains is distributed around $5 \mathrm{~nm}$. According to a FTIR study of the adsorption of water on ultradispersed diamond powder surface by Ji et al. [167], the surface of detonation nanodiamonds can naturally adsorb the water and hydrocarbon molecules from the environment atmosphere [167]. As the result of the research work by Iakoubovskii et al. using HRTEM, although the detonation nanodiamond grains were mostly cubic lattice, yet they were not perfect structures. According to the results of HRTEM, the main defects are shown as the multiple twins [166].

Applications of nanodiamonds cover a wide range, mainly including the commercial products such as the polishing products, additives to engine oils, reinforcing fillers for plastics and rubbers, dry lubricants for metal industry, and their applications in galvanic electrolytes. On the other hand, the recent researches on application of nanodiamonds in medical science particularly in chemotherapy drugs production are being performed.

3.3. Carbon Nanotubes. Due to the amazing structure and properties of CNTs, these materials have found great applications in very wide areas of science and technology including nanotechnology, electronics, optics, materials science, and architecture. In the view of the structural applications of CNTs, these applications cover a wide ranges of industrials such as clothes, sports equipment such as stronger and lighter tennis rackets, bike, various kinds of balls, combat jacket like combat jackets, concrete as the increase of the tensile strength, polyethylene, the possibility of the space elevator, synthetic muscles in medical science and sports, high tensile strength fibers, applications in the build of bridges, ultrahigh-speed flywheels, and applications in fire protection.

In electromagnetic field, the applications of CNTs are briefed in respect of their uses in chemical nanowires, conductive films, electric motor brushes, magnets, optical ignition, their applications to produce light bulb filament (as an alternative for tungsten filaments), the applications related to their fine superconductivity properties, in display screens such as field emission displays (FEDs), the applications in transistor industrial, and the electromagnetic antenna.

Other applications of CNTs are briefed in repect of their chemical applications, including air pollution filters, biotech containers, hydrogen storage, water filtration, and the mechanical applications such as using them as the faster oscillators, nanotube membrane, slick surface, carbon nanotube actuators, infrared detector, radiometric standard, and their application as the thermal radiation for space satellites.

This is worth to know that the wide range of applications of CNTs mentioned above is due to their unique mechanical, electrical, thermal, and optical properties which are briefly introduced in this section.

3.3.1. Strength. Carbon nanotubes (CNTs) are the strongest materials yet discovered, which is due to the covalent $\mathrm{sp}^{2}$ bonds between the individual carbon atoms. In 2000, Yu et al. [168] tested a multiwalled carbon nanotube (MWCNT) to access the tensile strength up to $63 \mathrm{GPa}$. The specific strength is defined as the material's strength (force per unit area at breaking point) divided by its density. Considering the low density of CNTs ( 1.3 to $1.4 \mathrm{~g} \mathrm{~cm}^{-3}$ ), the specific strength of CNTs is obtained up to $48 \times 10^{3} \mathrm{kN} \mathrm{m} \mathrm{kg}^{-1}$. This value is dramatically the best of the known materials.

To compare the strength property of various CNTs to some other strong materials such as stainless steel and kevlar, the tensile strength and Young's modulus of these materials have been briefed in Table 3 [168-175].

The first row of Table 3 shows the data for SWNT ropes based on the "experimental" measurements by Yu et al. using the microscopy method based on AFM [171, 173]. $\mathrm{Yu}$ et al. [173] measured the mechanical responses of 15 SWCNT ropes under the tensile load [173]. As they have stated in their paper [173], they considered all SWNT samples as $(10,10)$ nanotubes, with the measured diameter of $1.36 \mathrm{~nm}$ [173]. According to their experiments, as it is seen in Table 3, the average breaking strength value varies from 13 to $52 \mathrm{GPa}$ [173]. Furthermore, in the same evaluation, $\mathrm{Yu}$ et al. measured the average Young's modulus values of the SWNT rope samples equal to $1002 \mathrm{GP}$ (from 320 to $1470 \mathrm{GPa}$ or about $1 \mathrm{TP}$ in Table 3). In the same study, the failure strains occur at $16 \%$. In addition, Yu et al. reported the similar data for 19 samples of MWNTs. Based on their report [173], the strength and Young's modulus values for MWNT samples vary from 11 to $63 \mathrm{GPa}$ and 270 to $950 \mathrm{GPa}$, respectively (Table 3 ). In addition, Demczyk et al. [174] observed the force required to break the samples of MCNTs directly using transition electron microscopy. Based on the conducted pulling and bending tests on individual MWNTs, the mentioned researchers have measured the tensile strength and elastic modulus of MCNTs equal to $150 \mathrm{GPa}$ and $800 \mathrm{GPa}$, respectively [174].

On the other hand, the second and third rows of Table 3 show the related data as the "predicted" strength tensile values based on the analytical simulation models. Various "analytical" simulations and models have been recently applied to calculate the tensile and Young's modulus values for CNTs. An interesting model based on a molecular 
TABLE 3: Comparison of the mechanical properties of various nanotubes [168-175].

\begin{tabular}{lccc}
\hline Material & Tensile strength $(\mathrm{GPa})$ & Young's modulus $(\mathrm{GPa})$ & Failure strain $(\%)$ \\
\hline SWNT & 13 to 53 (measured) & $1002(\sim 1 \mathrm{TPa})$ (measured) & 16 \\
Armchair SWNT & 126.2 (predicted) & 940 (predicted) & 23.1 \\
Zigzag SWNT & 94.5 (predicted) & 940 (predicted) & $15.6-17.5$ \\
Chiral SWNT & - & 920 & - \\
MWNT & 11 to 150 & 186 to 214 & - \\
Stainless steel & 0.38 to 1.55 & 60 to 180 & 15 to 50 \\
Kevlar & 3.6 to 3.8 & $\sim 2$ \\
\hline
\end{tabular}

mechanics by Xiao et al. [175] predicts the maximum values of 126.2 GP and 94 GP for Armchair SWNT and Zigzag SWNT, respectively. As given in Table 3, the predicted failure strains in the study by Xiao et al. are $23.1 \%$ and within 15.6-17.5\% for armchair nanotubes and zigzag nanotubes, respectively [175].

Generally, as it is seen from Table 3, both the Young modulus and tensile strength of various carbon nanotubes are significantly more elevated than those for stainless steel and kevlar. It seems that CNTs are tended to a permanent deformation under a strong tensile strain. Furthermore, due to the hollow structure and high aspect ratio of CNTs, it seems that their strength is limited under compression or bending stress. On the other hand, as it can be seen from the simple geometry of CNT, carbon nanotubes should be softer in the radial direction than along the tube axis. In 1993, Ruoff et al. studied the Radial deformation of carbon nanotubes by van der Waals forces using transmission electron microscopy (TEM) [176]. According to their suggestion, two near nanotubes can be deformed even by van der Waals forces. Furthermore, according to the studies by Yu et al. in 2000 on radial deformability of individual carbon nanotubes under controlled indentation force (Figure 7) [177] and by Palaci et al. in 2005 [178] on radial elasticity of multiwalled carbon nanotubes, as can be seen in Figure 8, carbon nanotubes are rather soft in their radial direction.

3.3.2. Hardness. In 2002, Popov et al. [179] reported the synthesis of a super-hard phase (SP) composed of singlewall carbon nanotubes, measured by a nanoindenter within 62-152 GPa. The synthesis treatment was performed by compressing SWNTs to above $24 \mathrm{GPa}$ at room temperature. The authors considered the hardness of diamond and boron nitride samples (150 and $62 \mathrm{GPa}$, resp.) as mentioned in the references in their work [179]. The high mechanical properties of SP-SWNT, namely bulk modulus, were obtained as 462-546 GPa, surpassing the value of $420 \mathrm{GPa}$ for diamond [179]. The authors have found the hardness of SP-SWNT in the range of 62 to $150 \mathrm{GPa}$ and attributed SP-SWNT to the class of super-hard materials [179].

3.3.3. Electrical Properties. The electrical properties of a nanotube strongly depend on its structure due to the symmetrical and exceptionally electronic structure of graphene. For example, as shown in Figure 9, in a graphene crystal lattice, $n$ and $m$ are the number of unit vectors along two directions in which the graphene sheet is wrapped to make nanotube, so that $(n, m)$ is called the chiral vector. Zigzag nanotubes are formed by wrapping a graphene sheet whenever $m=0$, and in the same way, the structure is called armchair nanotube if $n=m$; Otherwise, they are called chiral nanotubes. In the view point of the electrical properties of CNTs, according to the model described by Lu et al. mentioned above [180], armchair nanotubes $(n=m)$ are metallic. On the other hand, if $n$ is not equal to $m$, however, $(n-m)$ is a multiple of 3 , the nanotube is semiconducting with a very small band gap; otherwise, the nanotube is a moderate semiconductor [180].

According to the mentioned rule, the structure of (5, 0) SWNTs should be semiconductor; however, exceptionally according to the calculations, due to the curvature effects in small diameter carbon nanotubes, this structure is metallic [180]. On the other hand, zigzag and chiral SWNTs with small diameters that are expected to be metallic have actually a finite gap [180].

In general, as Zhou et al. [181] have mentioned, SWNTs show excellent electronic properties such as the carrier mobility about $10^{4} \mathrm{~cm}^{2} \mathrm{~V}^{-1} \mathrm{~s}^{-1}$ [182] which is higher than that of silicon. On the other hand, as Dai et al. have described $[182,183]$, CNTs can carry an electrical current density of about $4 \times 10^{9} \mathrm{Acm}^{-2}$. Such a current density is three orders of magnitude higher than a typical metal, for example, $\mathrm{Cu}$ or $\mathrm{Al}[182]$.

Furthermore, in order to describe the electrical properties of multiwalled carbon nanotubes (MWNTs), it is worth to mention that, in 2006, Takesue et al. [184] have confirmed that the entirely end-banded MWNTs exhibit superconductivity with a transition temperature as high as $12 \mathrm{~K}$ which is approximately 30 times greater than that for ropes of SWNTs or for MWNTs with usually noninterconnected shells [184].

3.3.4. Thermal Properties of CNTs. As shown in Figure 10, the thermal conductivity of an SWNT at room temperature along its axis with the length $L \approx 2.6 \mu \mathrm{m}$ and the diameter $d \approx 1.7 \mathrm{~nm}$ was reported as $k \approx 3500 \mathrm{Wm}^{-1} \mathrm{~K}^{-1}$ by Pop et al. [185]. In order to compare the reported value by Pop et al. [185] with a good metallic thermal conductor, $\mathrm{Cu}$ shows a thermal conductivity about $385 \mathrm{Wm}^{-1} \mathrm{~K}^{-1}$. Furthermore, as Thostenson et al. [186] have mentioned, SWNTs show the stability to the temperature up to $2800^{\circ} \mathrm{C}$ in vacuum and $750^{\circ} \mathrm{C}$ in air, while metallic wires in microchips are melted at $600-1000^{\circ} \mathrm{C}[186]$. 


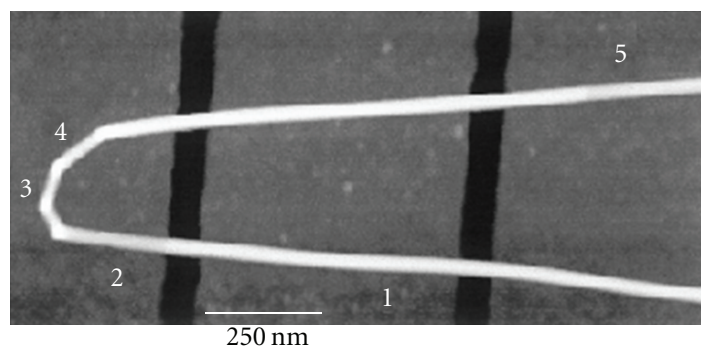

(a)

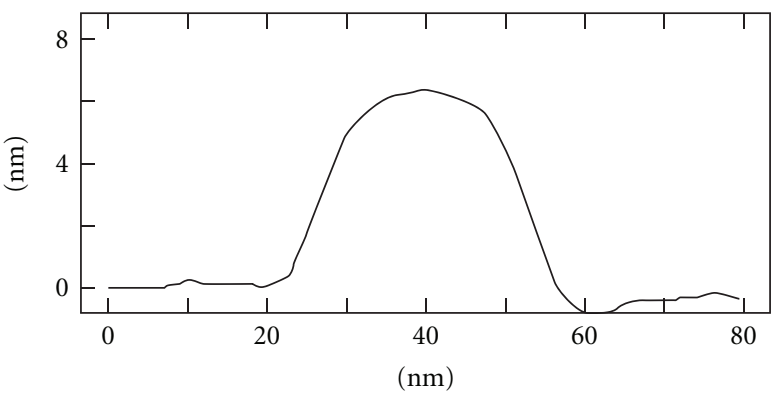

(b)

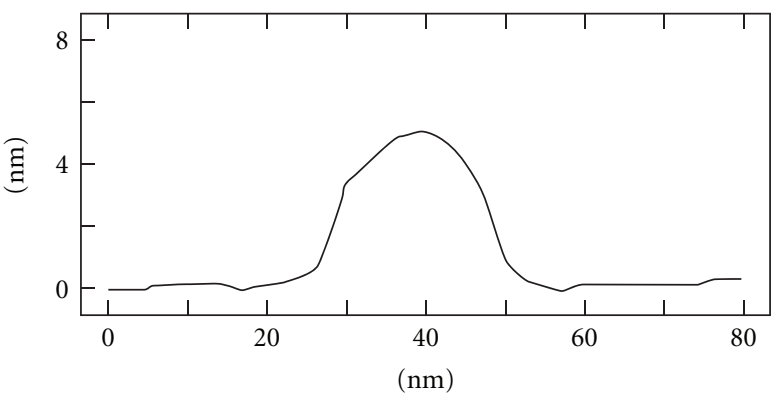

(c)

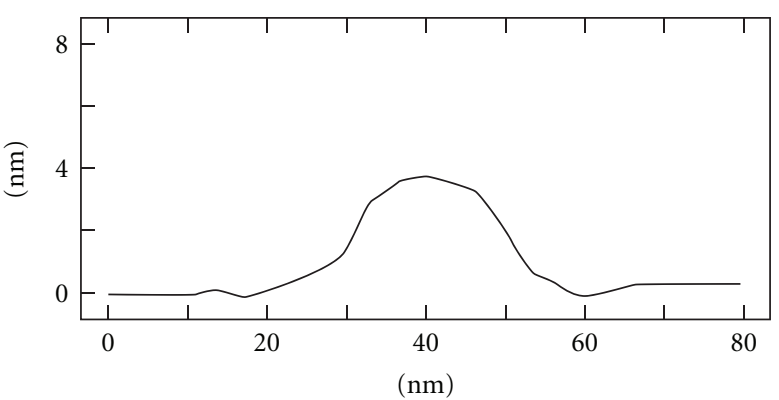

(d)

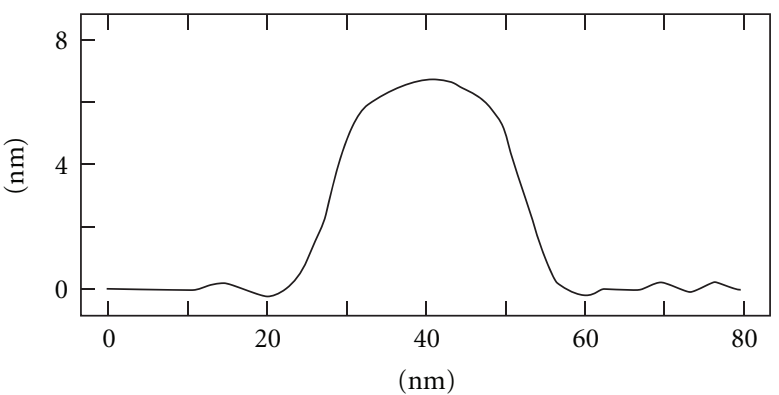

(e)

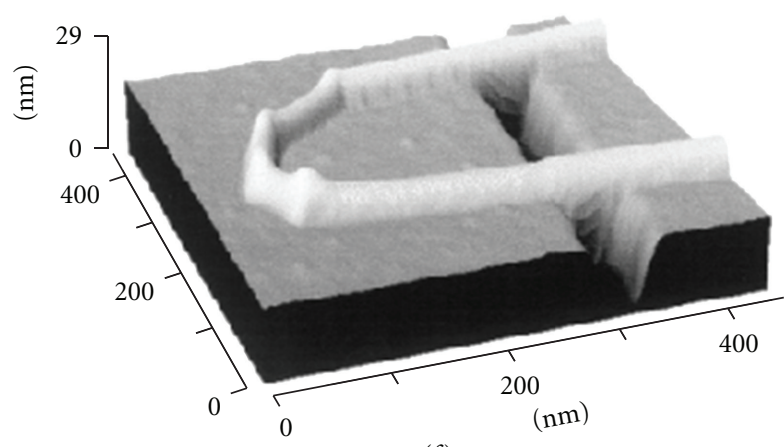

(f)

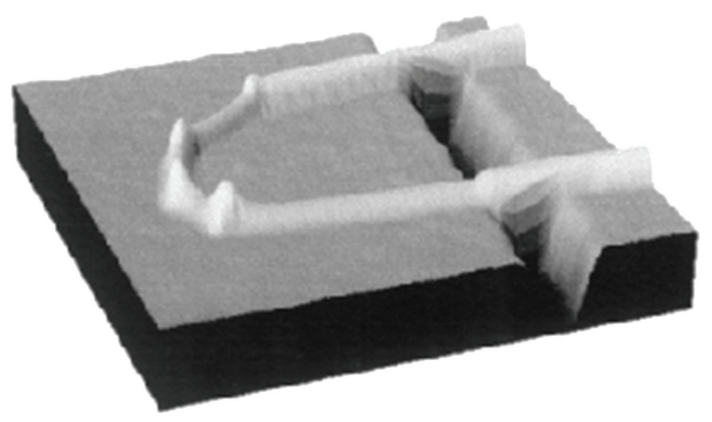

(g)

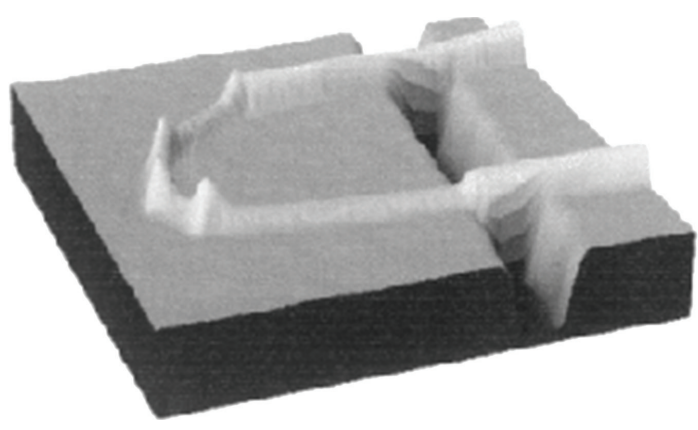

(h)

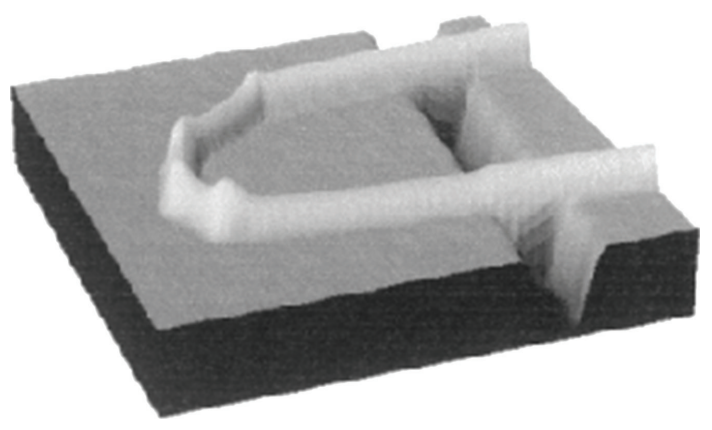

(i)

FIGURE 7: Deformability of a MWCNT deposited on an patterned silicon wafer as visualized with tapping-mode AFM operated far below mechanical resonance of a cantilever at different set points [177]. 


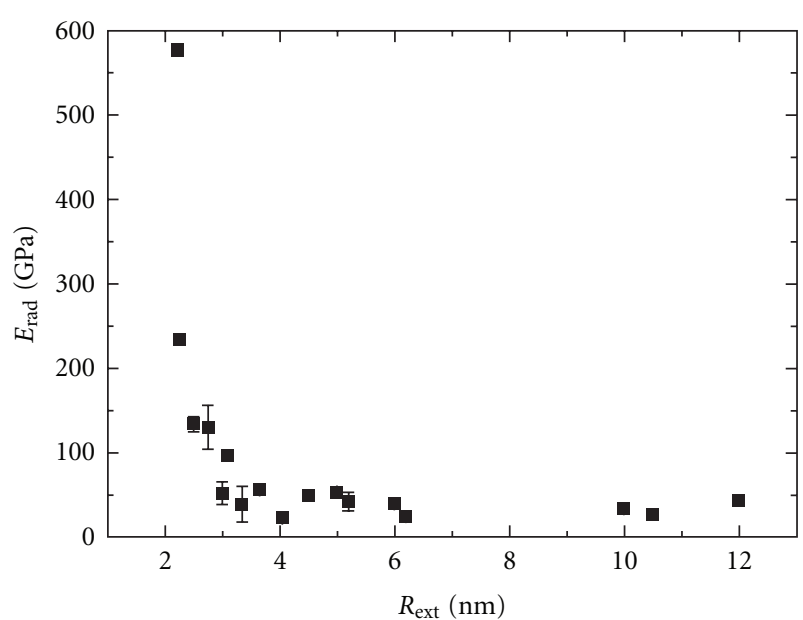

Figure 8: The radial Young modulus of CNTs as a function of $R_{\text {ext }}$, experimentally [178].

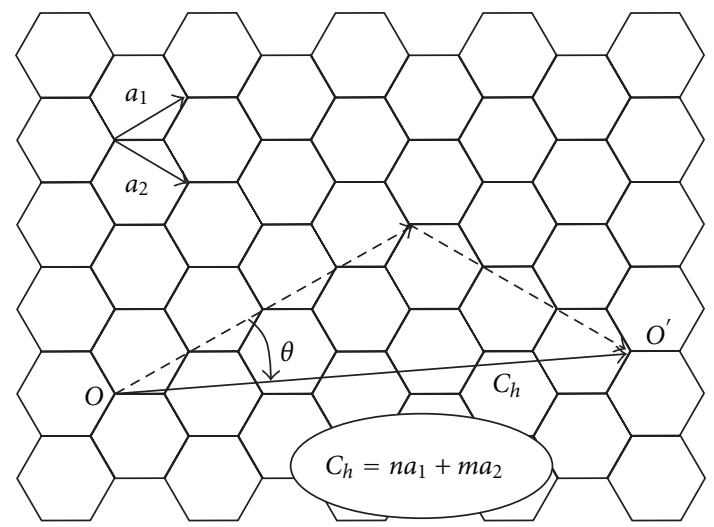

Figure 9: An $(n, m)$ SWCNT: roll-up vector $C_{h}=n a_{1}+m a_{2}$ and chiral angle $\tilde{o}$ (for this special case, $n=5, m=3 ; a_{1}$ and $a_{2}$ are the primitive vectors of a graphene sheet) [180].

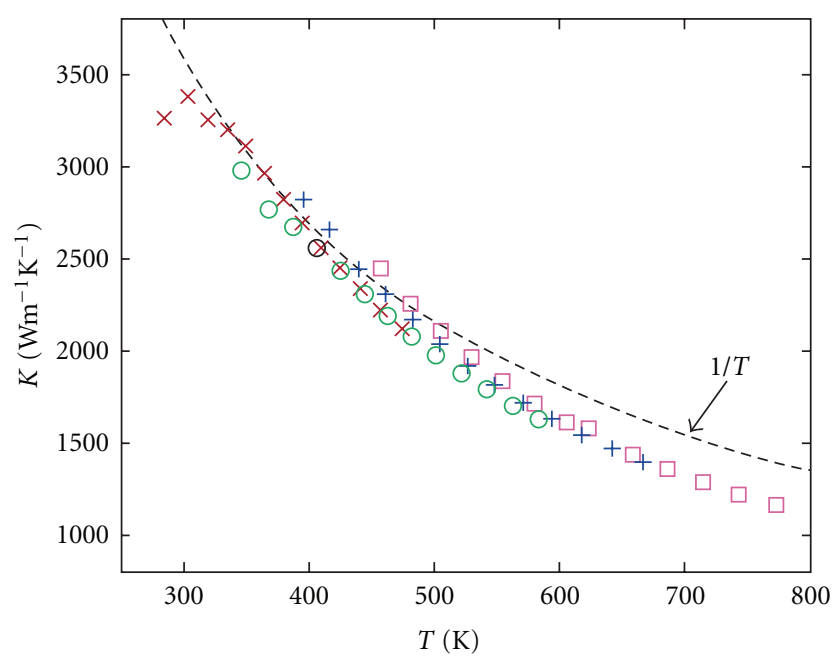

FIGURE 10: The relation between the extracted values of thermal conductivity and the average SWNT temperature [185].

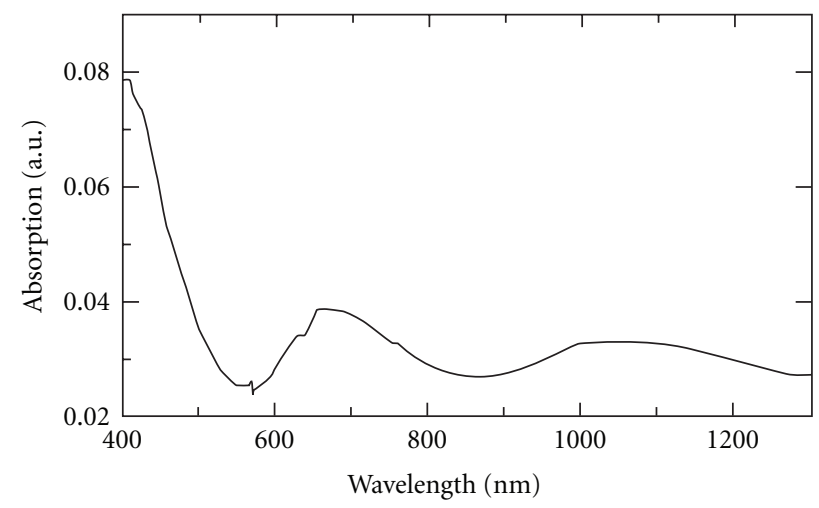

FIGURE 11: The adsorption spectrum of CNTs $[172,187]$.

3.3.5. Optical Absorption. The optical absorption in carbon nanotubes determined by Liu et al. [187] is shown in Figure 11. On the other hand, Margulis [188] has studied theoretically to indicate that zigzag SWNTs have positive lowfrequency third-order susceptibilities. The Optical absorption in CNTs is occurred due to the electronic transitions from the levels v2 to $\mathrm{c} 2$ or v1 to $\mathrm{c} 1$, and so forth $[172,189]$. The mentioned transition is sharp, so it can be used to identify the type of nanotube. As it was shown by Itkis et al. [190], optical absorption is used to obtain the quality of the CNTs' powders [191].

On the other hand, according to an interesting study by Mizuno et al. in 2009 [191], SWNTs can have absorbances of 0.98-0.99 from the far-ultraviolet $(200 \mathrm{~nm})$ to far-infrared $(200 \mu \mathrm{m})$ wavelengths. Therefore, compared to an ideal black body (with the absorbance of 1.0), a typical carbon nanotube is considered as a "practical black body" [191].

3.4. Graphene. In 2007, Meyer et al. [192] used transmission electron microscopy (TEM) to study the atomic structure of a single-layer graphene. As they reported, they have studied individual graphene sheets freely suspended on a microfabricated scaffold in vacuum or the air. The membranes were only one-atom thick, yet they still displayed longrange crystalline order [192]. According to their studies using TEM, the suspended graphene sheets are not perfectly flat. In other words, the suspended graphenes were observed as rippling of the flat sheet, with amplitude of about $1 \mathrm{~nm}$ [192]. As the authors explained, the atomically thin single-crystal membranes offered ample scope for fundamental research and new technologies, whereas the observed corrugations in the third dimension may provide subtle reasons for the stability of two-dimensional crystals [192].

3.4.1. Mobility of Graphene and the Applications. Graphene is known as a high electron mobility material at room temperature, so that the reported value is $15,000 \mathrm{~cm}^{2} \mathrm{~V}^{-1} \mathrm{~s}^{-1}$ [193]. In 2005, Novoselov et al. [194] considered graphene as a condensed-matter system in which electron transport is essentially governed by Dirac's (relativistic) equation [194]. In 2008, Morozov et al. [195] studied temperature dependences of electron transport in graphene and showed 
that the electron mobility higher than $2 \times 10^{5} \mathrm{~cm}^{2} \mathrm{~V}^{-1} \mathrm{~s}$ is achievable if extrinsic disorder is eliminated. In the same year, Chen et al. [196] studied the intrinsic and extrinsic performance limits of graphene devices on $\mathrm{SiO}_{2}$. According to the studies mentioned above, it seems that the electron mobility in graphene should be almost independent of the temperature between $10 \mathrm{~K}$ and $100 \mathrm{~K}$ [194-196].

Due to the high mobility of graphene, this material is known as a promising nanomaterial particularly for those applications in which transistors need to switch extremely fast. Furthermore, the high mobility of graphene involves this material in the applications related to chemical and biochemical sensing.

On the other hand, the resistivity of the graphene sheets is $10^{-6} \Omega \mathrm{cm}$ which is less than the resistivity of silver as known as the lowest resistivity at room temperature. Such a unique low resistivity and also the very low thickness of graphene have made this material to have a great role in many applications such as mechanical fields, electrical conducting, and transparent films which are necessarily applicable in the field of electronics such as producing touch screens and photovoltaic cells.

\section{Conclusion and the Future Outlooks}

As described in this paper, the unique structure and properties of low-dimensional carbon nanomaterials as the advanced materials have led them to have a strong and important potential role in various scientific fields and engineering such as nanoscale electronic devices, field emission displays, diodes, transistors, sensors, composite polymers, artificial muscles, mechanical reinforcements, capacitors, and hydrogen storage. For example, carbon nanobuds are the recently produced materials from two previously known allotropes of carbon nanotubes and fullerenes. These fullerene-like "buds" have found the unique properties of both fullerenes and CNTs which have many applications as good field emitters as well as their role to improve the mechanical properties of composites. As another example, the application of CNTs to develop the biofuel products is being noticeably growing due to their strongly deferent properties comparing to the previous products.

The list of companies which are working on the new features of carbon nanomaterials can show the importance of the use of these key materials in industry as well as the scientific areas. Taken the examples of such companies and their products, we can mention the Eagle Windpower Ltd. (windmills with lightweight blades), Easton (on bicycle components), Xintek (on Nanotube-based cathodes, AFM probes, and X-ray tubes), Nanomix (sensors for detecting chemical vapors), Nano-Proprietary, Inc. (analyzing chemicals in liquid samples), Zyvex Preformance Materials (epoxy resins strengthened with carbon nanotubes), Hyperion (Nanotube-based plastic mold compounds), Nano Lab (functionalized nanotubes and nanotube arrays), Nanoledge (Nanotube-based resins), Nanocs (Functionalized nanotubes), Nanocyl (nanotube-based epoxy resins), Amroy Europe Oy (Nanotube-based epoxy resins), Bayer Material
Science (Carbon nanotubes), Cheap Tubes (Carbon nanotubes), Catalytic Materials (Carbon nanotubes and graphite nanofibers), MER Corporation (Carbon nanotubes and buckyballs), NanoCarbLab (Carbon nanotubes), NanoAmor (Carbon nanotubes, carbon nanofibers, nanowires, and nanoparticles), Nanothinx (Carbon nanotubes), Rosseter Holdings (Carbon nanotubes), and many others.

As a matter of fact, due to the unique mechanical, optical, and electronic properties of carbon nanotubes, the publication statistics show that CNTs have successed to attract the main body of the authors' interest since 1991 up to now. However, as described in this paper, carbon nanomaterials are not limited to CNTs. Therefore, the future outlook of applications of these materials depends on the capability of the use of each one. As an interesting bioapplication example, nanodiamonds may be capable to be used for biolistic delivery in gene therapy, drug delivery, and vaccines as a solid support matrix. Furthermore, there is a strong possibility in near future to use nanodiamonds in the medical immunoassays as either the detection tag or the solid support matrix [197].

As the definition of the low-dimensional carbon nanomaterial, these materials also cover a wide range of carbonrelated nanostructurs such as nanodiamonds, fibers, cones, scrolls, whiskers, and graphite polyhedral crystals. In fact, there are expectable outlooks for the use of these materials in the fields of molecular electronics, sensoring, nanoelectromechanic devices, field-emission displays, energy storage, and composite materials, as well as their growing applications in medical science, health, and daily life [198].

\section{Acknowledgment}

This work was supported by Chang Jiang Scholars Program, China. The authors would like to express their appreciation to them. A. Mostofizadeh and Y. Li contributed equally to this work.

\section{References}

[1] M. Monthioux and V. L. Kuznetsov, "Who should be given the credit for the discovery of carbon nanotubes?" Carbon, vol. 44, no. 9, pp. 1621-1623, 2006.

[2] W. Bollmann and J. Spreadborough, "Action of graphite as a lubricant,” Nature, vol. 186, no. 4718, pp. 29-30, 1960.

[3] A. Oberlin, M. Endo, and T. Koyama, "Filamentous growth of carbon through benzene decomposition," Journal of Crystal Growth, vol. 32, no. 3, pp. 335-349, 1976.

[4] H. W. Kroto, J. R. Heath, S. C. O’Brien, R. F. Curl, and R. E. Smalley, "C60: buckminsterfullerene," Nature, vol. 318, no. 6042, pp. 162-163, 1985.

[5] S. Subramoney, "Novel nanocarbons-structure, properties, and potential applications," Advanced Materials, vol. 10, no. 15, pp. 1157-1171, 1998.

[6] T. Seyller, A. Bostwick, K. V. Emtsev et al., "Epitaxial graphene: a new material," Physica Status Solidi (B), vol. 245, no. 7, pp. 1436-1446, 2008.

[7] J. H. Kim, C. K. Kim, Y. H. Kim, and C. S. Yoon, "Synthesis of carbon-encapsulated gold nanoparticles in polyimide 
matrix," Colloids and Surfaces A, vol. 321, no. 1-3, pp. 297$300,2008$.

[8] L. Hawelek, A. Brodka, J. C. Dore, V. Honkimaki, S. Tomita, and A. Burian, "Structural studies of nanodiamond by highenergy X-ray diffraction," Diamond and Related Materials, vol. 17, no. 7-10, pp. 1186-1193, 2008.

[9] W. Xia, D. Su, A. Birkner et al., "Chemical vapor deposition and synthesis on carbon nanofibers: sintering of ferrocenederived supported iron nanoparticles and the catalytic growth of secondary carbon nanofibers," Chemistry of Materials, vol. 17, no. 23, pp. 5737-5742, 2005.

[10] O. Shenderova, V. Grishko, G. Cunningham, S. Moseenkov, G. McGuire, and V. Kuznetsov, "Onion-like carbon for terahertz electromagnetic shielding," Diamond and Related Materials, vol. 17, no. 4-5, pp. 462-466, 2008.

[11] S. Vizireanu, L. Nistor, M. Haupt, V. Katzenmaier, C. Oehr, and G. Dinescu, "Carbon nanowalls growth by radiofrequency plasma-beam-enhanced chemical vapor deposition," Plasma Processes and Polymers, vol. 5, no. 3, pp. 263-268, 2008.

[12] "The Nobel Prize in Chemistry 1996," Nobelprize.org, October 2010, http://nobelprize.org/nobel_prizes/chemistry/ laureates/1996/.

[13] W. Krätschmer, K. Fostiropoulos, and D. R. Huffman, “The infrared and ultraviolet absorption spectra of laboratoryproduced carbon dust: evidence for the presence of the $\mathrm{C}$ molecule," Chemical Physics Letters, vol. 170, no. 2-3, pp. 167-170, 1990.

[14] N. I. Alekseyev and G. A. Dyuzhev, "Fullerene formation in an arc discharge," Carbon, vol. 41, no. 7, pp. 1343-1348, 2003.

[15] J. B. Howard, J. T. McKinnon, Y. Makarovsky, A. L. Lafleur, and M. E. Johnson, "Fullerenes C60 and C70 in flames," Nature, vol. 352, no. 6331, pp. 139-141, 1991.

[16] J. B. Howard, A. L. Lafleur, Y. Makarovsky, S. Mitra, C. J. Pope, and T. K. Yadav, "Fullerenes synthesis in combustion," Carbon, vol. 30, no. 8, pp. 1183-1201, 1992.

[17] S. Y. Xie, R. B. Huang, L. J. Yu, J. Ding, and L. S. Zheng, "Microwave synthesis of fullerenes from chloroform," Applied Physics Letters, vol. 75, no. 18, pp. 2764-2766, 1999.

[18] R. Taylor, G. J. Langley, H. W. Kroto, and D. R. M. Walton, "Formation of C60 by pyrolysis of naphthalene," Nature, vol. 366, no. 6457, pp. 728-731, 1993.

[19] A. Koshio, M. Yudasaka, M. Ozawa, and S. Iijima, "Fullerene formation via pyrolysis of ragged single-wall carbon nanotubes," Nano Letters, vol. 2, no. 9, pp. 995-997, 2002.

[20] C. Chen and Z. Lou, "Formation of C60 by reduction of CO2," Journal of Supercritical Fluids, vol. 50, no. 1, pp. 4245, 2009.

[21] N. Koprinarov, M. Marinov, M. Konstantinova, and B. Ranguelov, "Fullerene structure synthesis by DC arc discharge in ferrocene vapours," Vacuum, vol. 58, no. 2, pp. 208214, 2000.

[22] H. Richter, E. De Hoffmann, R. Doome et al., "Fullerene formation in acetylene/oxygen/argon/chlorine flames," Carbon, vol. 34, no. 6, pp. 797-803, 1996.

[23] L. T. Scott, "Methods for the chemical synthesis of fullerenes," Angewandte Chemie-International Edition, vol. 43, no. 38, pp. 4994-5007, 2004.

[24] R. S. Ruoff, D. C. Lorents, B. Chan, R. Malhotra, and S. Subramoney, "Single crystal metals encapsulated in carbon nanoparticles," Science, vol. 259, no. 5093, pp. 346-348, 1993.

[25] M. Tomita, Y. Saito, and T. Hayashi, "LaC encapsulated in graphite nano-particle," Japanese Journal of Applied Physics, vol. 32, no. 2, pp. L280-L282, 1993.
[26] Y. Saito, "Nanoparticles and filled nanocapsules," Carbon, vol. 33, no. 7, pp. 979-988, 1995.

[27] V. P. Dravid, J. J. Host, M. H. Teng et al., "Controlled-size nanocapsules,” Nature, vol. 374, no. 6523, p. 602, 1995.

[28] J. J. Host, J. A. Block, K. Parvin et al., "Effect of annealing on the structure and magnetic properties of graphite encapsulated nickel and cobalt nanocrystals," Journal of Applied Physics, vol. 83, no. 2, pp. 793-801, 1998.

[29] J. Jiao, S. Seraphin, X. Wang, and J. C. Withers, "Preparation and properties of ferromagnetic carbon-coated $\mathrm{Fe}, \mathrm{Co}$, and Ni nanoparticles," Journal of Applied Physics, vol. 80, no. 1, pp. 103-108, 1996.

[30] J. Jiao and S. Seraphin, "Carbon encapsulated nanoparticles of $\mathrm{Ni}, \mathrm{Co}, \mathrm{Cu}$, and Ti," Journal of Applied Physics, vol. 83, no. 5, pp. 2442-2448, 1998.

[31] J. Qiu, Y. Li, Y. Wang, Z. Zhao, Y. Zhou, and Y. Wang, "Synthesis of carbon-encapsulated nickel nanocrystals by arc-discharge of coal-based carbons in water," Fuel, vol. 83, no. 4-5, pp. 615-617, 2004.

[32] P. J. F. Harris and S. C. Tsang, "A simple technique for the synthesis of filled carbon nanoparticles," Chemical Physics Letters, vol. 293, no. 1-2, pp. 53-58, 1998.

[33] E. Flahaut, F. Agnoli, J. Sloan, C. O’Connor, and M. L. H. Green, "CCVD Synthesis and characterization of cobaltencapsulated nanoparticles," Chemistry of Materials, vol. 14, no. 6, pp. 2553-2558, 2002.

[34] Z. H. Wang, C. J. Choi, B. K. Kim, J. C. Kim, and Z. D. Zhang, "Characterization and magnetic properties of carbon-coated cobalt nanocapsules synthesized by the chemical vaporcondensation process," Carbon, vol. 41, no. 9, pp. 1751-1758, 2003.

[35] S. H. Tsai, C. L. Lee, C. W. Chao, and H. C. Shih, "Novel technique for the formation of carbon-encapsulated metal nanoparticles on silicon," Carbon, vol. 38, no. 5, pp. 781-785, 2000.

[36] B. H. Liu, J. Ding, Z. Y. Zhong, Z. L. Dong, T. White, and J. Y. Lin, "Large-scale preparation of carbon-encapsulated cobalt nanoparticles by the catalytic method," Chemical Physics Letters, vol. 358, no. 1-2, pp. 96-102, 2002.

[37] Y. F. Zhang, Y. H. Tang, Y. Zhang, C. S. Lee, I. Bello, and S. T. Lee, "Deposition of carbon nanotubes on Si nanowires by chemical vapor deposition," Chemical Physics Letters, vol. 330, no. 1-2, pp. 48-52, 2000.

[38] Y. Lu, Z. Zhu, and Z. Liu, "Carbon-encapsulated Fe nanoparticles from detonation-induced pyrolysis of ferrocene," Carbon, vol. 43, no. 2, pp. 369-374, 2005.

[39] W. Wu, Z. Zhu, Z. Liu, Y. Xie, J. Zhang, and T. Hu, "Preparation of carbon-encapsulated iron carbide nanoparticles by an explosion method," Carbon, vol. 41, no. 2, pp. 317-321, 2003.

[40] J. N. Wang, LI. Zhang, F. Yu, and Z. M. Sheng, "Synthesis of carbon encapsulated magnetic nanoparticles with giant coercivity by a spray pyrolysis approach," Journal of Physical Chemistry B, vol. 111, no. 8, pp. 2119-2124, 2007.

[41] H. Song and X. Chen, "Large-scale synthesis of carbonencapsulated iron carbide nanoparticles by co-carbonization of durene with ferrocene," Chemical Physics Letters, vol. 374, no. 3-4, pp. 400-404, 2003.

[42] J. Huo, H. Song, and X. Chen, "Preparation of carbonencapsulated iron nanoparticles by co-carbonization of aromatic heavy oil and ferrocene," Carbon, vol. 42, no. 15, pp. 3177-3182, 2004. 
[43] M. Bystrzejewski, H. Lange, A. Huczko, H. I. Elim, and W. Ji, "Study of the optical limiting properties of carbonencapsulated magnetic nanoparticles," Chemical Physics Letters, vol. 444, no. 1-3, pp. 113-117, 2007.

[44] J. B. Park, S. H. Jeong, M. S. Jeong, J. Y. Kim, and B. K. Cho, "Synthesis of carbon-encapsulated magnetic nanoparticles by pulsed laser irradiation of solution," Carbon, vol. 46, no. 11, pp. 1369-1377, 2008.

[45] J. Nishijo, C. Okabe, O. Oishi, and N. Nishi, "Synthesis, structures and magnetic properties of carbon-encapsulated nanoparticles via thermal decomposition of metal acetylide," Carbon, vol. 44, no. 14, pp. 2943-2949, 2006.

[46] F. Maya, S. Muhl, O. Peña, and M. Miki-Yoshida, "Synthesis and characterization of silver-carbon nanoparticles produced by high-current pulsed arc," Thin Solid Films, vol. 518, no. 5, pp. 1484-1488, 2009.

[47] F. P. Bundy, H. T. Hall, H. M. Strong, and R. H. Wentorf, "Man-Made diamonds," Nature, vol. 176, no. 4471, pp. 51$55,1955$.

[48] A. M. Staver, N. V. Gubareva, A. I. Lyamkin et al., "The flow in a shock tube in the presence of suspended particles," Fizika Goreniya I Vzryza, vol. 20, no. 5, 1984.

[49] N. R. Greiner, D. S. Phillips, J. D. Johnson, and F. Volk, "Diamonds in detonation soot," Nature, vol. 333, no. 6172, pp. 440-442, 1988.

[50] K. Iakoubovskii, M. V. Baidakova, B. H. Wouters et al., "Structure and defects of detonation synthesis nanodiamond," Diamond and Related Materials, vol. 9, no. 3-6, pp. 861-865, 2000.

[51] P. W. Chen, Y. S. Ding, Q. Chen, F. L. Huang, and S. R. Yun, "Spherical nanometer-sized diamond obtained from detonation," Diamond and Related Materials, vol. 9, no. 9, pp. 1722-1725, 2000.

[52] T. Hamilton, E. Z. Kurmaev, S. N. Shamin, P. Y. Detkov, S. I. Chukhaeva, and A. Moewes, "Soft X-ray absorption and emission characterization of nanodiamond prepared by explosive detonation," Diamond and Related Materials, vol. 16, no. 2, pp. 350-352, 2007.

[53] X. Xu, Z. Yu, Y. Zhu, and B. Wang, "Influence of surface modification adopting thermal treatments on dispersion of detonation nanodiamond," Journal of Solid State Chemistry, vol. 178, no. 3, pp. 688-693, 2005.

[54] Q. Zou, M. Z. Wang, Y. G. Li, L. H. Zou, H. Yu, and Y. C. Zhao, "Analysis of structures and surface states of the nanodiamond particle synthesised by detonation," Micro and Nano Letters, vol. 4, no. 3, pp. 133-141, 2009.

[55] V. Gupta, P. Scharff, and N. Miura, "Synthesis of diamond by electron irradiation of C60 intercalated graphite," Materials Letters, vol. 59, no. 26, pp. 3259-3261, 2005.

[56] V. S. Purohit, D. Jain, V. G. Sathe, V. Ganesan, and S. V. Bhoraskar, "Synthesis of nanocrystalline diamonds by microwave plasma," Journal of Physics D, vol. 40, no. 6, pp. 1794-1800, 2007.

[57] T. Sharda, T. Soga, T. Jimbo, and M. Umeno, "Biased enhanced growth of nanocrystalline diamond films by microwave plasma chemical vapor deposition," Diamond and Related Materials, vol. 9, no. 7, pp. 1331-1335, 2000.

[58] M. Nagatsu, M. Miyake, and J. Maeda, "Plasma CVD reactor with two-microwave oscillators for diamond film synthesis," Thin Solid Films, vol. 506-507, pp. 617-621, 2006.

[59] T. Hao, H. Zhang, C. Shi, and G. Han, "Nano-crystalline diamond films synthesized at low temperature and low pressure by hot filament chemical vapor deposition," Surface and Coatings Technology, vol. 201, no. 3-4, pp. 801-806, 2006.
[60] L. Vandenbulcke, T. Gries, and J. N. Rouzaud, "Nanodiamonds in dusty low-pressure plasmas," Applied Physics Letters, vol. 94, no. 4, Article ID 044106, 2009.

[61] L. Yang, P. W. May, L. Yin, J. A. Smith, and K. N. Rosser, "Growth of diamond nanocrystals by pulsed laser ablation of graphite in liquid," Diamond and Related Materials, vol. 16, no. 4-7, pp. 725-729, 2007.

[62] C. Wen, Z. Jin, X. Liu et al., "Synthesis of diamond using nano-graphite and Fe powder under high pressure and high temperature," Materials Letters, vol. 60, no. 29-30, pp. 35073510, 2006.

[63] L. Hawelek, A. Brodka, J. C. Dore, V. Honkimaki, S. Tomita, and A. Burian, "Structural studies of nanodiamond by highenergy X-ray diffraction," Diamond and Related Materials, vol. 17, no. 7-10, pp. 1186-1193, 2008.

[64] D. Amans, A. C. Chenus, G. Ledoux et al., "Nanodiamond synthesis by pulsed laser ablation in liquids," Diamond and Related Materials, vol. 18, no. 2-3, pp. 177-180, 2009.

[65] D. Ugarte, "Curling and closure of graphitic networks under electron-beam irradiation," Nature, vol. 359, no. 6397, pp. 707-709, 1992.

[66] P. J. F. Harris and S. C. Tsang, "High-resolution electron microscopy studies of non-graphitizing carbons," Philosophical Magazine A, vol. 76, no. 3, pp. 667-677, 1997.

[67] D. Ugarte, "Morphology and structure of graphitic soot particles generated in arc-discharge C production," Chemical Physics Letters, vol. 198, no. 6, pp. 596-602, 1992.

[68] W. Kratschmer, L. D. Lamb, K. Fostiropoulos, and D. R. Huffman, "Solid C60: a new form of carbon," Nature, vol. 347, no. 6291, pp. 354-358, 1990.

[69] B. S. Xu and S. I. Tanaka, "Formation of giant onion-like fullerenes under $\mathrm{Al}$ nanoparticles by electron irradiation," Acta Materialia, vol. 46, no. 15, pp. 5249-5257, 1998.

[70] A. G. Nasibulin, A. Moisala, D. P. Brown, and E. I. Kauppinen, "Carbon nanotubes and onions from carbon $\mathrm{n}$ monoxide using $\mathrm{Ni}(\mathrm{acac}) 2$ and $\mathrm{Cu}(\mathrm{acac}) 2$ as catalyst precursors," Carbon, vol. 41, no. 14, pp. 2711-2724, 2003.

[71] J. S. Qiu, Y. Zhou, L. N. Wang, and S. C. Tsang, "Formation of carbon nanotubes and encapsulated nanoparticles from coals with moderate ash contents," Carbon, vol. 36, no. 4, pp. 465467, 1998.

[72] T. Cabioc'h, E. Thune, and M. Jaouen, "Carbon-onion thinfilm synthesis onto silica substrates," Chemical Physics Letters, vol. 320, no. 1-2, pp. 202-205, 2000.

[73] T. Cabioc'h, M. Jaouen, M. F. Denanot, and P. Bechet, "Influence of the implantation parameters on the microstructure of carbon onions produced by carbon ion implantation," Applied Physics Letters, vol. 73, no. 21, pp. 3096-3098, 1998.

[74] H. Abe, "Nucleation of carbon onions and nanocapsules under ion implantation at high temperature," Diamond and Related Materials, vol. 10, no. 3-7, pp. 1201-1204, 2001.

[75] V. L. Kuznetsov, A. L. Chuvilin, Y. V. Butenko, I. Y. Mal'kov, and V. M. Titov, "Onion-like carbon from ultra-disperse diamond," Chemical Physics Letters, vol. 222, no. 4, pp. 343348, 1994.

[76] L. G. Bulusheva, A. V. Okotrub, V. L. Kuznetsov, and D. V. Vyalikh, "Soft X-ray spectroscopy and quantum chemistry characterization of defects in onion-like carbon produced by nanodiamond annealing," Diamond and Related Materials, vol. 16, no. 4-7, pp. 1222-1226, 2007.

[77] M. Bystrzejewski, M. H. Rummeli, T. Gemming, H. Lange, and A. Huczko, "Catalyst-free synthesis of onion-like carbon nanoparticles," New Carbon Materials, vol. 25, no. 1, pp. 1-8, 2010. 
[78] M. Zhao, H. Song, X. Chen, and W. Lian, "Large-scale synthesis of onion-like carbon nanoparticles by carbonization of phenolic resin," Acta Materialia, vol. 55, no. 18, pp. 61446150, 2007.

[79] X. Liu, C. Wang, Y. Yang, X. Guo, H. Wen, and B. Xu, "Synthesis of nano onion-like fullerenes by using Fe/Al2O3 as catalyst by chemical vapor deposition," Chinese Science Bulletin, vol. 54, no. 1, pp. 137-141, 2009.

[80] A. B. Du, X. G. Liu, D. J. Fu, P. D. Han, and B. S. Xu, "Onionlike fullerenes synthesis from coal," Fuel, vol. 86, no. 1-2, pp. 294-298, 2007.

[81] J. Huang, Y. Liu, and T. You, "Carbon nanofiber based electrochemical biosensors: a review," Analytical Methods, vol. 2, no. 3, pp. 202-211, 2010.

[82] P. Serp, M. Corrias, and P. Kalck, "Carbon nanotubes and nanofibers in catalysis," Applied Catalysis A, vol. 253, no. 2, pp. 337-358, 2003.

[83] S. Iijima, "Helical microtubules of graphitic carbon," Nature, vol. 354, no. 6348, pp. 56-58, 1991.

[84] E. P. S. Tan, C. N. Goh, C. H. Sow, and C. T. Lim, “Tensile test of a single nanofiber using an atomic force microscope tip," Applied Physics Letters, vol. 86, no. 7, Article ID 073115, 3 pages, 2005.

[85] E. P. S. Tan and C. T. Lim, "Mechanical characterization of nanofibers-a review," Composites Science and Technology, vol. 66, no. 9, pp. 1099-1108, 2006.

[86] H. J. Qi, K. B. K. Teo, K. K. S. Lau et al., "Determination of mechanical properties of carbon nanotubes and vertically aligned carbon nanotube forests using nanoindentation," Journal of the Mechanics and Physics of Solids, vol. 51, no. 1112, pp. 2213-2237, 2003.

[87] P. E. Aderson and N. M. Rodriguez, "Influence of the support on the structural characteristics of carbon nanofibers produced from the metal-catalyzed decomposition of ethylene," Chemistry of Materials, vol. 12, no. 3, pp. 823-830, 2000.

[88] A. Tanaka, S. H. Yoon, and I. Mochida, "Preparation of highly crystalline nanofibers on $\mathrm{Fe}$ and $\mathrm{Fe}-\mathrm{Ni}$ catalysts with a variety of graphene plane alignments," Carbon, vol. 42, no. 3, pp. 591-597, 2004.

[89] G. L. Bezemer, P. B. Radstake, U. Falke et al., "Investigation of promoter effects of manganese oxide on carbon nanofibersupported cobalt catalysts for Fischer-Tropsch synthesis," Journal of Catalysis, vol. 237, no. 1, pp. 152-161, 2006.

[90] S. Takenaka, M. Ishida, M. Serizawa, E. Tanabe, and K. Otsuka, "Formation of carbon nanofibers and carbon nanotubes through methane decomposition over supported cobalt catalysts," Journal of Physical Chemistry B, vol. 108, no. 31, pp. 11464-11472, 2004.

[91] J. P. Tu, L. P. Zhu, K. Hou, and S. Y. Guo, "Synthesis and frictional properties of array film of amorphous carbon nanofibers on anodic aluminum oxide," Carbon, vol. 41, no. 6, pp. 1257-1263, 2003.

[92] V. Z. Mordkovich, "Carbon nanofibers: a new ultrahighstrength material for chemical technology," Theoretical Foundations of Chemical Engineering, vol. 37, no. 5, pp. 429-438, 2003.

[93] A. De Lucas, P. B. García, A. Garrido, A. Romero, and J. L. Valverde, "Catalytic synthesis of carbon nanofibers with different graphene plane alignments using $\mathrm{Ni}$ deposited on iron pillared clays," Applied Catalysis A, vol. 301, no. 1, pp. 123-132, 2006.

[94] K. Takehira, T. Ohi, T. Shishido, T. Kawabata, and K. Takaki, "Catalytic growth of carbon fibers from methane and ethylene on carbon-supported Ni catalysts," Applied Catalysis A, vol. 283, no. 1-2, pp. 137-145, 2005.

[95] D. Y. Ding, J. N. Wang, and A. Dozier, "Symmetry-related growth of carbon nanocoils from Ni-P based alloy particles," Journal of Applied Physics, vol. 95, no. 9, pp. 5006-5009, 2004.

[96] K. L. Klein, A. V. Melechko, P. D. Rack, J. D. Fowlkes, H. M. Meyer, and M. L. Simpson, "Cu-Ni composition gradient for the catalytic synthesis of vertically aligned carbon nanofibers," Carbon, vol. 43, no. 9, pp. 1857-1863, 2005.

[97] A. R. Naghash, Z. Xu, and T. H. Etsell, "Coprecipitation of nickel-copper-aluminum takovite as catalyst precursors for simultaneous production of carbon nanofibers and hydrogen," Chemistry of Materials, vol. 17, no. 4, pp. 815-821, 2005.

[98] F. Yuan, H. K. Yu, and H. Ryu, "Preparation and characterization of carbon nanofibers as catalyst support material for PEMFC," Electrochimica Acta, vol. 50, no. 2-3, pp. 685-691, 2004.

[99] W. C. Ren and H. M. Cheng, "Herringbone-type carbon nanofibers with a small diameter and large hollow core synthesized by the catalytic decomposition of methane," Carbon, vol. 41, no. 8, pp. 1657-1660, 2002.

[100] Y. Qin, Z. Zhang, and Z. Cui, "Helical carbon nanofibers with a symmetric growth mode," Carbon, vol. 42, no. 10, pp. 19171922, 2004.

[101] C. Singh, T. Quested, C. B. Boothroyd et al., "Synthesis and characterization of carbon nanofibers produced by the floating catalyst method," Journal of Physical Chemistry B, vol. 106, no. 42, pp. 10915-10922, 2002.

[102] C. Pham-Huu, N. Keller, V. V. Roddatis, G. Mestl, R. Schlögl, and M. J. Ledoux, "Large scale synthesis of carbon nanofibers by catalytic decomposition of ethane on nickel nanoclusters decorating carbon nanotubes," Physical Chemistry Chemical Physics, vol. 4, no. 3, pp. 514-521, 2002.

[103] G. Zou, D. Zhang, C. Dong et al., "Carbon nanofibers: synthesis, characterization, and electrochemical properties," Carbon, vol. 44, no. 5, pp. 828-832, 2006.

[104] L. Yu, L. Sui, Y. Qin, and Z. Cui, "Low-temperature synthesis of carbon nanofibers by decomposition of acetylene with a catalyst derived from cupric nitrate," Chemical Engineering Journal, vol. 144, no. 3, pp. 514-517, 2008.

[105] J. Zhang, I. Khatri, N. Kishi, T. Soga, and T. Jimbo, "Synthesis of carbon nanofibers using C60, graphite and boron," Materials Letters, vol. 64, no. 11, pp. 1243-1246, 2010.

[106] T. Kimura, H. Koizumi, H. Kinoshita, and T. Ichikawa, "Formation of carbon nanofibers from decacyclene by ion beam irradiation," Nuclear Instruments and Methods in Physics Research B, vol. 236, no. 1-4, pp. 474-481, 2005.

[107] Y. Matsumoto, M. Than Oo, M. Nakao, K. Kamimura, Y. Onuma, and H. Matsushima, "Preparation of carbon nanofibers by hot filament-assisted sputtering," Materials Science and Engineering B, vol. 74, no. 1, pp. 218-221, 2000.

[108] M. Guláš, M. Čaplovičová, M. Michalka et al., "Growth of carbon nanofibers and related structures by combined method of plasma enhanced chemical vapor deposition and aerosol synthesis," Vacuum, vol. 82, no. 8, pp. 805-813, 2008.

[109] P. Ren, X. Zou, J. Cheng et al., "Synthesis of carbon nanofibers by ethanol catalytic combustion technique," Advanced Materials Research, vol. 24-25, pp. 731-734, 2007.

[110] L. Ci, Y. Li, B. Wei, J. Liang, C. Xu, and D. Wu, "Preparation of carbon nanofibers by the floating catalyst method," Carbon, vol. 38, no. 14, pp. 1933-1937, 2000. 
[111] S. Mori and M. Suzuki, "Effect of oxygen and hydrogen addition on the low-temperature synthesis of carbon nanofibers using a low-temperature CO/Ar DC plasma," Diamond and Related Materials, vol. 17, no. 6, pp. 999-1002, 2008.

[112] S. Iijima, "Helical microtubules of graphitic carbon," Nature, vol. 354, no. 6348, pp. 56-58, 1991.

[113] T. W. Ebbesen and P. M. Ajayan, "Large-scale synthesis of carbon nanotubes," Nature, vol. 358, no. 6383, pp. 220-222, 1992.

[114] S. Iijima and T. Ichihashi, "Single-shell carbon nanotubes of 1-nm diameter," Nature, vol. 363, no. 6430, pp. 603-605, 1993.

[115] D. S. Bethune, C. H. Kiang, M. S. De Vries et al., "Cobaltcatalysed growth of carbon nanotubes with single-atomiclayer walls," Nature, vol. 363, no. 6430, pp. 605-607, 1993.

[116] C. Journet, W. K. Maser, P. Bernier et al., "Large-scale production of single-walled carbon nanotubes by the electric-arc technique," Nature, vol. 388, no. 6644, pp. 756-758, 1997.

[117] A. Thess, R. Lee, P. Nikolaev et al., "Crystalline ropes of metallic carbon nanotubes," Science, vol. 273, no. 5274, pp. 483-487, 1996.

[118] M. Yacaman, M. Yoshida, L. Rendon, and J. G. Santiesteban, "Catalytic growth of carbon microtubules with fullerene structure," Applied Physics Letters, vol. 62, no. 2, pp. 202-204, 1993.

[119] E. Flahaut, A. Govindaraj, A. Peigney, CH. Laurent, A. Rousset, and C. N. R. Rao, "Synthesis of single-walled carbon nanotubes using binary ( $\mathrm{Fe}, \mathrm{Co}, \mathrm{Ni}$ ) alloy nanoparticles prepared in situ by the reduction of oxide solid solutions," Chemical Physics Letters, vol. 300, no. 1-2, pp. 236-242, 1999.

[120] H. Dai, "Carbon nanotubes: opportunities and challenges," Surface Science, vol. 500, no. 1-3, pp. 218-241, 2002.

[121] V. N. Popov, "Carbon nanotubes: properties and application," Materials Science and Engineering R, vol. 43, no. 3, pp. 61-102, 2004.

[122] P. M. Ajayan and T. W. Ebbesen, "Nanometre-size tubes of carbon," Reports on Progress in Physics, vol. 60, no. 10, pp. 1025-1062, 1997.

[123] Q. Zeng, Z. Li, and Y. Zhou, "Synthesis and application of carbon nanotubes," Journal of Natural Gas Chemistry, vol. 15, no. 3, pp. 235-246, 2006.

[124] E. S. Thiele and R. H. French, "Computation of light scattering by anisotropic spheres of rutile titania," Advanced Materials, vol. 10, no. 15, pp. 1271-1276, 1998.

[125] W. Zhou, X. Bai, E. Wang, and S. Xie, "Synthesis, structure, and properties of single-walled carbon nanotubes," Advanced Materials, vol. 21, no. 45, pp. 4565-4583, 2009.

[126] D. S. Arensburger, S. M. Zimakov, P. A. Kulu, and M. A. Oyaviir, "Coatings deposited by the high-velocity flame spraying method," Powder Metallurgy and Metal Ceramics, vol. 40, no. 3-4, pp. 127-134, 2001.

[127] A. Huczko, "Synthesis of aligned carbon nanotubes," Applied Physics A, vol. 74, no. 5, pp. 617-638, 2002.

[128] C. N. R. Rao, B. C. Satishkumar, A. Govindaraj, and M. Nath, "Nanotubes," ChemPhysChem, vol. 2, no. 2, pp. 78-105, 2001.

[129] S. N. Bondi, W. J. Lackey, R. W. Johnson, X. Wang, and Z. L. Wang, "Laser assisted chemical vapor deposition synthesis of carbon nanotubes and their characterization," Carbon, vol. 44, no. 8, pp. 1393-1403, 2006.

[130] K. S. Novoselov, A. K. Geim, S. V. Morozov et al., "Electric field in atomically thin carbon films," Science, vol. 306, no. 5696, pp. 666-669, 2004.
[131] K. S. Novoselov, D. Jiang, F. Schedin et al., "Two-dimensional atomic crystals," Proceedings of the National Academy of Sciences of the United States of America, vol. 102, no. 30, pp. 10451-10453, 2005.

[132] K. S. Novoselov, A. K. Geim, S. V. Morozov et al., "Chiral tunnelling and the Klein paradox in graphene," Nature, vol. 438, pp. 197-200, 2005.

[133] A. K. Geim and K. S. Novoselov, "The rise of graphene," Nature Materials, vol. 6, no. 3, pp. 183-191, 2007.

[134] K. S. Kim, Y. Zhao, H. Jang et al., "Large-scale pattern growth of graphene films for stretchable transparent electrodes," Nature, vol. 457, no. 7230, pp. 706-710, 2009.

[135] V. Y. Aristov, G. Urbanik, K. Kummer et al., "Graphene synthesis on cubic SiC/Si wafers. Perspectives for mass production of graphene-based electronic devices," Nano Letters, vol. 10, no. 3, pp. 992-995, 2010.

[136] W. S. Hummers and R. E. Offeman, "Preparation of graphitic oxide," Journal of the American Chemical Society, vol. 80, no. 6, p. 1339, 1958.

[137] M. J. McAllister, JE. L. Li, D. H. Adamson et al., "Single sheet functionalized graphene by oxidation and thermal expansion of graphite," Chemistry of Materials, vol. 19, no. 18, pp. 43964404, 2007.

[138] J. Chattopadhyay, A. Mukherjee, C. E. Hamilton et al., "Graphite epoxide," Journal of the American Chemical Society, vol. 130, no. 16, pp. 5414-5415, 2008.

[139] S. Chandra, S. Sahu, and P. Pramanik, "A novel synthesis of graphene by dichromate oxidation," Materials Science and Engineering B, vol. 167, no. 3, pp. 133-136, 2010.

[140] S. Stankovich, D. A. Dikin et al., "High-yield production of graphene by liquid-phase," Carbon, vol. 45, pp. 1558-1565, 2007.

[141] V. C. Tung, M. J. Allen, Y. Yang, and R. B. Kaner, "Facile synthesis and characterization of graphene nanosheets," Nature Nanotechnology, vol. 4, pp. 25-29, 2009.

[142] W. Guoxiu, Y. Juan, P. Jinsoo et al., "Facile synthesis and characterization of graphene nanosheets," Journal of Physical Chemistry C, vol. 112, no. 22, pp. 8192-8195, 2008.

[143] Y. Si and E. T. Samulski, "Synthesis of water soluble graphene," Nano Letters, vol. 8, no. 6, pp. 1679-1682, 2008.

[144] X. Fan, W. Peng, Y. Li et al., "Deoxygenation of exfoliated graphite oxide under alkaline conditions: a green route to graphene preparation," Advanced Materials, vol. 20, no. 23, pp. 4490-4493, 2008.

[145] G. Williams, B. Seger, and P. V. Kamt, "TiO ${ }_{2}$-graphene nanocomposites. UV-assisted photocatalytic reduction of graphene oxide," ACS Nano, vol. 2, no. 7, pp. 1487-1491, 2008.

[146] S. Wakeland, R. Martinez, J. K. Grey, and C. C. Luhrs, "Production of graphene from graphite oxide using urea as expansion-reduction agent," Carbon, vol. 48, no. 12, pp. 3463-3470, 2010.

[147] W. Chen, L. Yan, and P. R. Bangal, "Preparation of graphene by the rapid and mild thermal reduction of graphene oxide induced by microwaves," Carbon, vol. 48, no. 4, pp. 11461152, 2010.

[148] Y. Wu, P. Qiao, T. Chong, and Z. Shen, "Carbon nanowalls grown by microwave plasma enhanced chemical vapor deposition," Advanced Materials, vol. 14, no. 1, pp. 64-67, 2002.

[149] K. Shiji, M. Hiramatsu, A. Enomoto, M. Nakamura, H. Amano, and M. Hori, "Vertical growth of carbon nanowalls 
using rf plasma-enhanced chemical vapor deposition," Diamond and Related Materials, vol. 14, no. 3-7, pp. 831-834, 2005.

[150] M. Hiramatsu, K. Shiji, H. Amano, and M. Hori, "Fabrication of vertically aligned carbon nanowalls using capacitively coupled plasma-enhanced chemical vapor deposition assisted by hydrogen radical injection," Applied Physics Letters, vol. 84, no. 23, pp. 4708-4710, 2004.

[151] T. Itoh, S. Shimabukuro, S. Kawamura, and S. Nonomura, "Preparation and electron field emission of carbon nanowall by Cat-CVD," Thin Solid Films, vol. 501, no. 1-2, pp. 314-317, 2006.

[152] S. Shimabukuro, Y. Hatakeyama, M. Takeuchi, T. Itoh, and S. Nonomura, "Effect of hydrogen dilution in preparation of carbon nanowall by hot-wire CVD," Thin Solid Films, vol. 516, no. 5, pp. 710-713, 2008.

[153] T. Mori, M. Hiramatsu, K. Yamakawa, K. Takeda, and M. Hori, "Fabrication of carbon nanowalls using electron beam excited plasma-enhanced chemical vapor deposition," Diamond and Related Materials, vol. 17, no. 7-10, pp. 15131517, 2008.

[154] S. Vizireanu, L. Nistor, M. Haupt, V. Katzenmaier, C. Oehr, and G. Dinescu, "Carbon nanowalls growth by radiofrequency plasma-beam-enhanced chemical vapor deposition," Plasma Processes and Polymers, vol. 5, no. 3, pp. 263-268, 2008.

[155] A. T. H. Chuang, B. O. Boskovic, and J. Robertson, "Freestanding carbon nanowalls by microwave plasma-enhanced chemical vapour deposition," Diamond and Related Materials, vol. 15, no. 4-8, pp. 1103-1106, 2006.

[156] J. J. Wang, M. Y. Zhu, R. A. Outlaw et al., "Free-standing subnanometer qraphite sheets," Applied Physics Letters, vol. 85, no. 7, pp. 1265-1267, 2004.

[157] G. Sato, T. Kato, W. Oohara, and R. Hatakeyama, "Production and application of reactive plasmas using helicon-wave discharge in very low magnetic fields," Thin Solid Films, vol. 506-507, pp. 550-554, 2006.

[158] R. C. Haddon, A. F. Hebard, M. J. Rosseinsky et al., "Conducting films of C60 and C70 by alkali-metal doping," Nature, vol. 350, no. 6316, pp. 320-322, 1991.

[159] A. F. Hebard, M. J. Rosseinsky, R. C. Haddon et al., "Superconductivity at $18 \mathrm{~K}$ in potassium-doped C60," Nature, vol. 350, no. 6319, pp. 600-601, 1991.

[160] M. J. Rosseinsky, A. P. Ramirez, S. H. Glarum et al., "Superconductivity at $28 \mathrm{~K}$ in RbxC60", Physical Review Letters, vol. 66, no. 21, pp. 2830-2832, 1991.

[161] C. C. Chen, S. P. Kelty, and C. M. Lieber, "(RbK)C superconductors: formation of a continuous series of solid solutions," Science, vol. 253, no. 5022, pp. 886-888, 1991.

[162] O. Zhou, G. B. M. Vaughan, Q. Zhu et al., "Compressibility of M3C60 fullerene superconductors: relation between Tc and lattice parameter," Science, vol. 255, no. 5046, pp. 833-835, 1992.

[163] C. M. Brown, T. Takenobu, K. Kordatos, K. Prassides, Y. Iwasa, and K. Tanigaki, "Pressure dependence of superconductivity in the Na2Rb0.5Cs0.5C60 fulleride," Physical Review B, vol. 59, no. 6, pp. 4439-4444, 1999.

[164] A. Y. Ganin, Y. Takabayashi, Y. Z. Khimyak et al., "Bulk superconductivity at $38 \mathrm{~K}$ in a molecular system," Nature Materials, vol. 7, no. 5, pp. 367-371, 2008.

[165] http://www.nanodiamond.co.kr/.

[166] K. Iakoubovskii, K. Mitsuishi, and K. Furuya, "Highresolution electron microscopy of detonation nanodia- mond," Nanotechnology, vol. 19, no. 15, Article ID 155705, 2008.

[167] S. Ji, T. Jiang, K. Xu, and S. Li, "FTIR study of the adsorption of water on ultradispersed diamond powder surface," Applied Surface Science, vol. 133, no. 4, pp. 231-238, 1998.

[168] M.-F. Yu, O. Lourie, M. J. Dyer, K. Moloni, T. F. Kelly, and R. S. Ruoff, "Strength and breaking mechanism of multiwalled carbon nanotubes under tensile load," Science, vol. 287, no. 5453, pp. 637-640, 2000.

[169] S. Bellucci, "Carbon nanotubes: physics and applications," Physica Status Solidi (c), vol. 2, no. 1, pp. 34-47, 2005.

[170] H. G. Chae and S. Kumar, "Rigid-rod polymeric fibers," Journal of Applied Polymer Science, vol. 100, no. 1, pp. 791802, 2006.

[171] M. Meo and M. Rossi, "Prediction of Young's modulus of single wall carbon nanotubes by molecular-mechanics based finite element modeling," Composites Science and Technology, vol. 66, no. 11-12, pp. 1597-1605, 2006.

[172] S. B. Sinnott and R. Andrews, "Carbon nanotubes: synthesis, properties, and applications," Critical Reviews in Solid State and Materials Sciences, vol. 26, no. 3, pp. 145-249, 2001.

[173] M.-F. Yu, B. S. Files, S. Arepalli, and R. S. Ruoff, "Tensile loading of ropes of single wall carbon nanotubes and their mechanical properties," Physical Review Letters, vol. 84, no. 24, pp. 5552-5555, 2000.

[174] B. G. Demczyk, Y. M. Wang, J. Cumings et al., "Direct mechanical measurement of the tensile strength and elastic modulus of multiwalled carbon nanotubes," Materials Science and Engineering A, vol. 334, no. 1-2, pp. 173-178, 2002.

[175] J. R. Xiao, B. A. Gama, and J. W. Gillespie, "An analytical molecular structural mechanics model for the mechanical properties of carbon nanotubes," International Journal of Solids and Structures, vol. 42, no. 11-12, pp. 3075-3092, 2005.

[176] R. S. Ruoff, J. Tersoff, D. C. Lorents, S. Subramoney, and B. Chan, "Radial deformation of carbon nanotubes by van der Waals forces," Nature, vol. 364, no. 6437, pp. 514-516, 1993.

[177] M.-F. Yu, T. Kowalewski, and R. S. Ruoff, "Investigation of the radial deformability of individual carbon nanotubes under controlled indentation force," Physical Review Letters, vol. 85, no. 7, pp. 1456-1459, 2000.

[178] I. Palaci, S. Fedrigo, H. Brune, C. Klinke, M. Chen, and E. Riedo, "Radial elasticity of multiwalled carbon nanotubes," Physical Review Letters, vol. 94, no. 17, Article ID 175502, 2005.

[179] M. Popov, M. Kyotani, R. J. Nemanich, and Y. Koga, "Superhard phase composed of single-wall carbon nanotubes," Physical Review B, vol. 65, no. 3, pp. 334081-334084, 2002.

[180] X. Lu and Z. Chen, "Curved Pi-conjugation, aromaticity, and the related chemistry of small fullerenes $\left(<\mathrm{C}_{60}\right)$ and singlewalled carbon nanotubes," Chemical Reviews, vol. 105, no. 10, pp. 3643-3696, 2005.

[181] X. Zhou, J.-Y. Park, S. Huang, J. Liu, and P. L. McEuen, "Band structure, phonon scattering, and the performance limit of single-walled carbon nanotube transistors," Physical Review Letters, vol. 95, no. 14, Article ID 146805, 4 pages, 2005.

[182] H. Dai, A. Javey, E. Pop, D. Mann, and Y. Lu, "Electrical transport properties and field-effect transistors of carbon nanotubes," NANO: Brief Reports and Reviews, vol. 1, no. 1, pp. 1-4, 2006.

[183] A. Javey, P. Qi, Q. Wang, and H. Dai, “Ten- to 50-nm-long quasi-ballistic carbon nanotube devices obtained without complex lithography," Proceedings of the National Academy of Sciences of the United States of America, vol. 101, no. 37, pp. 13408-13410, 2004. 
[184] I. Takesue, J. Haruyama, N. Kobayashi et al., "Superconductivity in entirely end-bonded multiwalled carbon nanotubes," Physical Review Letters, vol. 96, no. 5, Article ID 057001, 2006.

[185] E. Pop, D. Mann, Q. Wang, K. Goodson, and H. Dai, "Thermal conductance of an individual single-wall carbon nanotube above room temperature," Nano Letters, vol. 6, no. 1, pp. 96-100, 2006.

[186] E. T. Thostenson, C. Li, and T. W. Chou, "Nanocomposites in context," Composites Science and Technology, vol. 65, no. 3-4, pp. 491-516, 2005.

[187] X. Liu, J. Si, B. Chang et al., "Third-order optical nonlinearity of the carbon nanotubes," Applied Physics Letters, vol. 74, no. 2, pp. 164-166, 1999.

[188] VL. A. Margulis, "Theoretical estimations of third-order optical nonlinearities for semiconductor carbon nanotubes," Journal of Physics Condensed Matter, vol. 11, no. 15, pp. 30653074, 1999.

[189] H. Kataura, Y. Kumazawa, Y. Maniwa et al., "Optical properties of single-wall carbon nanotubes," Synthetic Metals, vol. 103, no. 1-3, pp. 2555-2558, 1999.

[190] M. E. Itkis, D. E. Perea, R. Jung, S. Niyogi, and R. C. Haddon, "Comparison of analytical techniques for purity evaluation of single-walled carbon nanotubes," Journal of the American Chemical Society, vol. 127, no. 10, pp. 3439-3448, 2005.

[191] K. Mizuno, J. Ishii, H. Kishida et al., "A black body absorber from vertically aligned single-walled carbon nanotubes," Proceedings of the National Academy of Sciences of the United States of America, vol. 106, no. 15, pp. 6044-6047, 2009.

[192] J. C. Meyer, A. K. Geim, M. I. Katsnelson, K. S. Novoselov, T. J. Booth, and S. Roth, "The structure of suspended graphene sheets," Nature, vol. 446, no. 7131, pp. 60-63, 2007.

[193] A. K. Geim and K. S. Novoselov, "The rise of graphene," Nature Materials, vol. 6, no. 3, pp. 183-191, 2007.

[194] K. S. Novoselov, A. K. Geim, S. V. Morozov et al., "Twodimensional gas of massless Dirac fermions in graphene," Nature, vol. 438, no. 7065, pp. 197-200, 2005.

[195] S. V. Morozov, K. S. Novoselov, M. I. Katsnelson et al., "Giant intrinsic carrier mobilities in graphene and its bilayer," Physical Review Letters, vol. 100, no. 1, Article ID 016602, 6 pages, 2008.

[196] J. H. Chen, C. Jang, S. Xiao, M. Ishigami, and M. S. Fuhrer, "Intrinsic and extrinsic performance limits of graphene devices on SiO2," Nature Nanotechnology, vol. 3, no. 4, pp. 206-209, 2008.

[197] M. S. Amanda, A. Suzanne, H. Ciftan, and S. A. Olga, "Nanodiamond particles: properties and perspectives for bioapplications," Critical Reviews in Solid State and Materials Sciences, vol. 34, no. 1-2, pp. 18-74, 2009.

[198] Y. Gogotsi, Ed., Carbon Nanomaterials, CRC Press, 2006. 

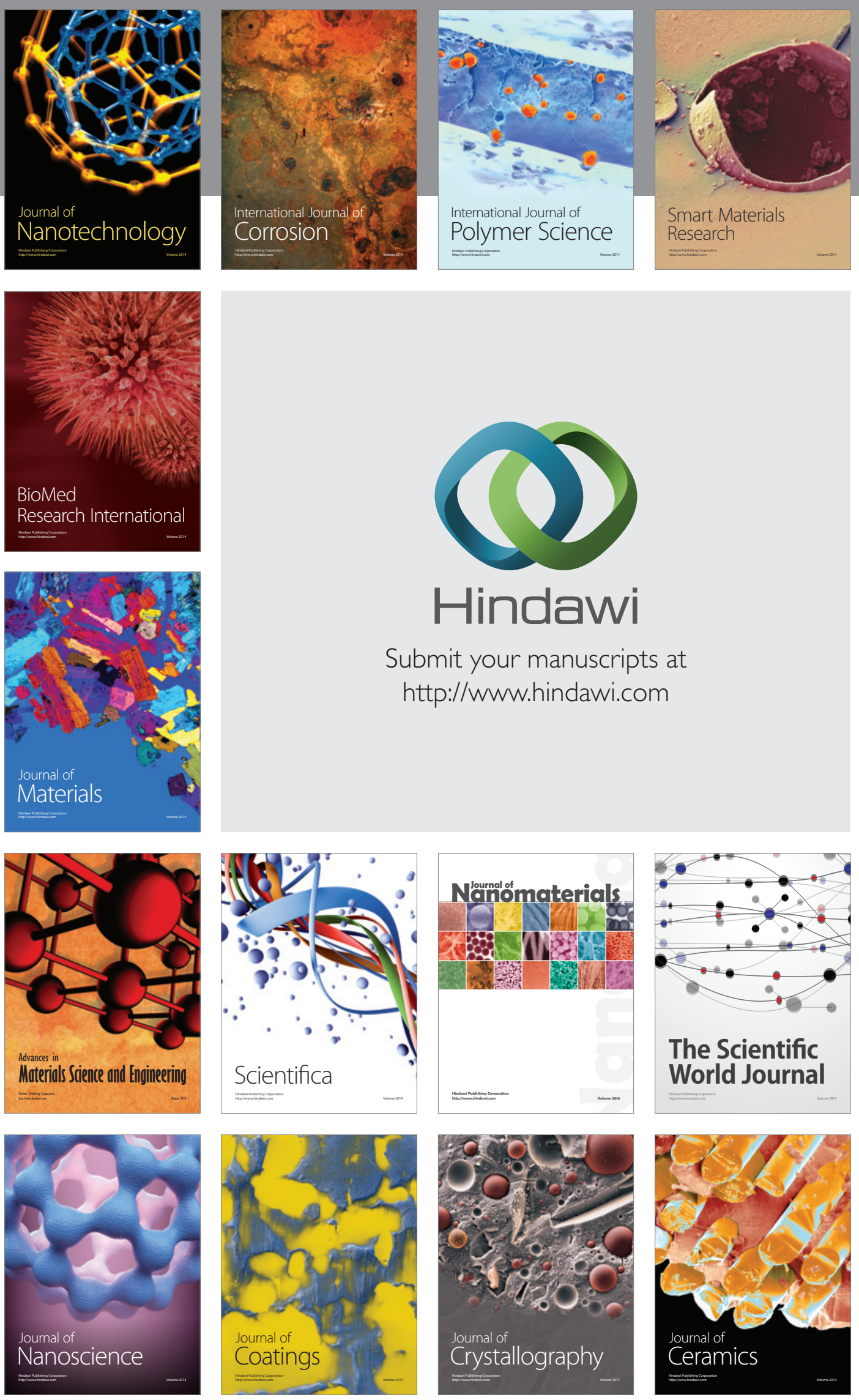

The Scientific World Journal

Submit your manuscripts at

http://www.hindawi.com

\section{World Journal}

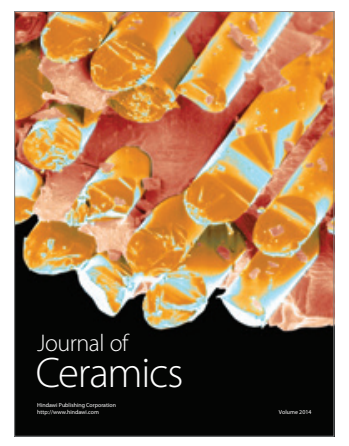

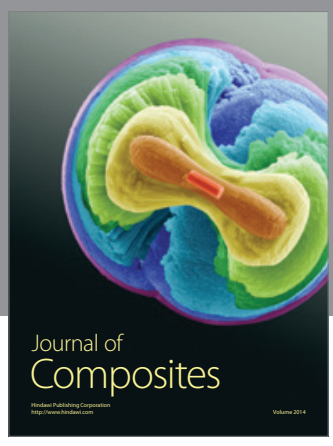
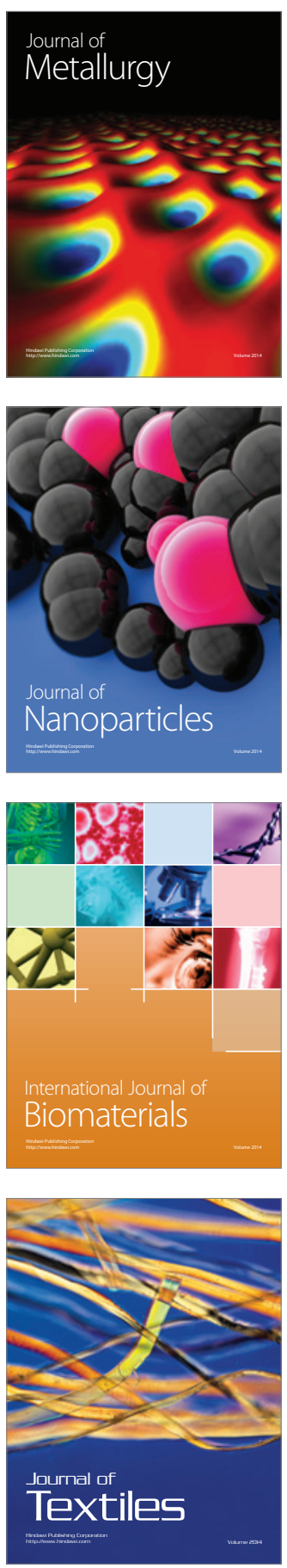